\title{
Multi-modal analysis of aerosol robotic network size distributions for remote sensing applications: dominant aerosol type cases
}

\author{
M. Taylor, S. Kazadzis, and E. Gerasopoulos \\ Institute for Environmental Research and Sustainable Development (IERSD), National Observatory of Athens (NOA), \\ Metaxa \& Vas Pavlou, Penteli, 15236, Athens, Greece
}

Correspondence to: M. Taylor (patternizer@gmail.com)

Received: 3 November 2013 - Published in Atmos. Meas. Tech. Discuss.: 9 December 2013

Revised: 14 February 2014 - Accepted: 20 February 2014 - Published: 31 March 2014

\begin{abstract}
To date, size distributions obtained from the aerosol robotic network (AERONET) have been fit with bilognormals defined by six secondary microphysical parameters: the volume concentration, effective radius, and the variance of fine and coarse particle modes. However, since the total integrated volume concentration is easily calculated and can be used as an accurate constraint, the problem of fitting the size distribution can be reduced to that of deducing a single free parameter - the mode separation point. We present a method for determining the mode separation point for equivalent-volume bi-lognormal distributions based on optimization of the root mean squared error and the coefficient of determination. The extracted secondary parameters are compared with those provided by AERONET's Level 2.0 Version 2 inversion algorithm for a set of benchmark dominant aerosol types, including desert dust, biomass burning aerosol, urban sulphate and sea salt. The total volume concentration constraint is then also lifted by performing multimodal fits to the size distribution using nested Gaussian mixture models, and a method is presented for automating the selection of the optimal number of modes using a stopping condition based on Fisher statistics and via the application of statistical hypothesis testing. It is found that the method for optimizing the location of the mode separation point is independent of the shape of the aerosol volume size distribution (AVSD), does not require the existence of a local minimum in the size interval $0.439 \mu \mathrm{m} \leq r \leq 0.992 \mu \mathrm{m}$, and shows some potential for optimizing the bi-lognormal fitting procedure used by AERONET particularly in the case of desert dust aerosol. The AVSD of impure marine aerosol is found to require three modes. In this particular case, bi-lognormals fail to recover key features of the AVSD. Fitting the AVSD more
\end{abstract}

generally with multi-modal models allows automatic detection of a statistically significant number of aerosol modes, is applicable to a very diverse range of aerosol types, and gives access to the secondary microphysical parameters of additional modes currently not available from bi-lognormal fitting methods.

\section{Introduction}

\section{Highlights}

- A method for optimizing bi-lognormal fits to the size distribution with a single free parameter - the mode separation point.

- Sensitivity analysis of the dependence of secondary microphysical parameters on the mode separation point and on aerosol optical depth.

- A method for multi-modal analysis of the size distribution using Gaussian mixture models and access to the microphysical parameters of higher modes.

- A test of the feasibility of the methods for fitting size distributions of dominant aerosol types of diverse morphology.

As reported by Sayer et al. (2012), the retrieval of parameters such as the aerosol optical depth (AOD) from satellite measurements is accomplished by algorithms that model the optical characteristics of columnar aerosol (the spectral scattering phase function, single scattering albedo and extinction coefficient) via parameters of microphysical structure, 
including the aerosol volume size distribution (AVSD) and the spectral complex refractive index. Retrievals are therefore rather sensitive to the choice of model of particle size and composition. Furthermore, difficulties are compounded by the fact that the complete set of required parameters cannot presently be obtained unambiguously (Hasekamp and Landgraf, 2007) especially when the spectral and directional behaviour of the surface reflectance is unknown (Kokhanovsky et al., 2010).

So, while the ability of satellite retrieval algorithms to represent the radiative behaviour of real aerosols is still in question (most recently raised in the context of pure marine aerosol models by Sayer et al., 2012), satellite retrievals are usually validated (e.g. Remer et al., 2005) against colocated and synchronous retrievals provided by ground-based Sun photometer and sky radiometer systems like those in the aerosol robotic network (AERONET). The main reason for this is that remote sensing of the AVSD in particular is exceedingly difficult and no one sensor system is capable yet of providing totally unambiguous information (King et al., 2009). Moreover, the aerosol model intercomparison initiative AeroCom (Aerosol Comparisons between Observation and Models) has carried out analysis of aerosol simulations from various global chemical transport and climate models and found that, even on the scale of yearly averages, aerosol life cycles and particle sizes span a large range of values (Textor et al., 2006, 2007) and the total number of aerosol modes, mode composition and control parameters vary considerably both between models and their final simulation results (Zhang et al., 2010). As a result, there is heavy reliance on the AVSDs provided by AERONET.

The advanced mathematical inversion algorithm developed to provide AERONET retrievals (Dubovik and King, 2000) from direct (Sun) and diffuse (sky) measurements of radiation returns aerosol optical parameters such as the spectral AOD, single scattering albedo and phase function, as well as important microphysical parameters like the AVSD, the complex refractive index, and the percentage of spherical particles (see Dubovik et al., 2002, 2006). Since the AVSD plays a pivotal role in the relation of the radiation field to the microphysics of aerosol particles (Hansen and Travis, 1974) as well as for the determination of aerosol type and composition (Dubovik et al., 2011), this paper focuses on the development of a method for assessing whether or not the AVSD for a couple of characteristic cases can be fit using multiple aerosol modes with a procedure that can be automated.

The AERONET Level 2.0 Version 2 inversion code inverts sky radiances simultaneously at wavelengths available in the CIMEL instrument (most frequently at 440, 675, 870 and $1020 \mathrm{~nm}$ ) for the complete solar almucantar scenario or principal plane scenario together with measurements of $\mathrm{AOD}$ at the operational wavelengths. In particular, the algorithm returns the AVSD $\mathrm{d} V(r) / \mathrm{d} \ln r$ in 22 equidistant logarithmic radial size bins spanning the range of particle radii $0.05 \leq r \leq 15 \mu \mathrm{m}$, normalized to the value of the total volume concentration of aerosol in $\mu \mathrm{m}^{3} / \mu \mathrm{m}^{2}$. The AERONET inversion code approximates the AVSD using trapezium rule integration (Dubovik and King, 2000), and, while the option of allowing the use of lognormal-shaped bins was included in Dubovik et al. (2006), it has only recently been found that sufficiently accurate modelling of POLDER/PARASOL observations requires such an optimization of the shape of each radial size bin (Dubovik et al., 2011). In particular, lognormal-shaped bins were found to provide notable improvements over the trapezoidal approximation in terms of smoothness and suggested some advantage in modelling the AVSD as a superposition of $n$ lognormals with the modal volume concentrations $V_{i}$, geometric mean radii $r_{i}$ and standard deviations $\sigma_{i}$ as fixed parameters (Dubovik et al., 2011):

$\frac{\mathrm{d} V(r)}{\mathrm{d} \ln r}=\sum_{i=1 . . n} \frac{V_{i}}{\sigma_{i} \sqrt{2 \pi}} e^{-\frac{1}{2}\left(\frac{\ln r-\ln r_{i}}{\sigma_{i}}\right)^{2}}$.

This finding is the main motivation for this paper. For several decades now, the AVSD of tropospheric aerosols has been known to contain several distinct modes, each most commonly being modelled by a lognormal function (Whitby, 1978; Remer et al., 1997, 1998; Remer and Kaufman, 1998; O'Neill et al., 2000). The statistical properties of the lognormal and bi-lognormal distribution are well known (O'Neill et al., 2000) and are applied in this paper to test the feasibility of modelling the AVSD of distinct aerosol cases with superpositions of several $(n \geq 2)$ lognormals. The multi-modal method presented here, it is hoped, will add a new layer of detail to existing studies without the need for too much additional mathematical complexity. Furthermore, since many available radiative-transfer codes are now able to take as input lognormal distribution parameters (Sayer et al., 2012), the results of this paper can be readily applied and implemented. In Appendix A, the equations used to calculate secondary microphysical parameters such as $V_{i}, r_{i}$ and $\sigma_{i}$ are presented.

The paper is organized as follows. The approach adopted for aerosol typing and the selection of sites impacted by dominant aerosol types is presented in Sect. 2. Section 3 then briefly outlines two new methods for optimizing bilognormal fits and for fitting the AVSD with multiple modes. In Sect. 4, the results of applying the two new methods to a cohort of AVSDs representative of different aerosol types are presented and compared with AERONET, and the major impacts and feasibility of these new approaches are noted and analysed. Finally, we conclude in Sect. 5 with a summary of our findings and an assessment of the potential offered by these new methods for analysing AVSDs provided by AERONET or other remote sensing instruments.

\section{Data selection}

In this paper we apply new methodologies (developed in Sect. 3) to a set of dominant aerosol type 
AVSDs. While portals like NASA's AERONET Data Synergy Tool (http://aeronet.gsfc.nasa.gov/cgi-bin/bamgomas interactive) and the Multi-sensor Aerosol Products Sampling System (MAPSS: http://giovanni.gsfc.nasa.gov/mapss) provide a framework for multi-sensor aerosol validation, intercomparison, and joint analysis, a search for dominant aerosol type cases and high-load aerosol events must still be done manually or with reference to field campaigns published in the literature. Here, we describe the approach we adopted to isolate candidate AERONET sites as well as those days which are most dominated by desert dust, biomass burning products, urban sulphate, and marine sea salt. We will see below that "dominant" sea salt is the most problematic case for bi-lognormal fitting methods owing to the fact that the data are drawn from an island site where the marine aerosol is mixed to a high degree (in the proportion $60 \%: 40 \%$ ) with other aerosol species.

The Georgia Institute of Technology-Goddard Global Ozone Chemistry Aerosol Radiation and Transport (GOCART) model (Chin et al., 2000, 2002; Ginoux et al., 2001) used by NASA's GEOS-5 simulates the AOD for major types of tropospheric aerosols. In particular, it provides 3-hourly measurements of the total AOD as well as the contribution to the total AOD of sulphate (SU), black carbon (BC), organic carbon (OC), desert (mineral) dust (DU) and sea salt (SS). It therefore provides a model-driven aerosol classification. This is complementary to the way the AERONET's Spectral Deconvolution Algorithm Product (O'Neill et al., 2003) uses a more generalized set of microphysical assumptions to estimate the contributions of fine and coarse particles to the AOD at visible wavelengths. GOCART data spanning the years 2001-2005 (inclusive) are obtainable from the AERONET data synergy portal and were downloaded for the first 155 AERONET sites (75\% of all Level $2.0 \mathrm{Ver}$ sion 2 Inversion Product records $N$ ) ranked by the number of daily-averaged data available. Since GOCART provides eight 3-hourly measurements per day, these were averaged to produce daily averages. The ratio of the contribution of individual aerosol types to the total AOD was then calculated (as percentages) and used to sort the ranked sites by dominant ("nearly pure") aerosol type. This approach provides a simple and straightforward method for site selection. During this process, an additional column was added to the data provided by GOCART so as to monitor a combination of aerosol: the combined percentage of organic and black carbon $(\mathrm{OC}+\mathrm{BC})$. The reason for this is that, although $\mathrm{SU}$ accompanies the burning of biomass products, the combination $\mathrm{OC}+\mathrm{BC}$ was found to better distinguish biomass burning sites from urban sites (which can also have high levels of SU). While no site of course has $100 \%$ "pure" aerosol of a single type, this approach enables one to rank sites by dominant aerosol type. For example, for the biomass burning products $\mathrm{OC}+\mathrm{BC}$, Mongu was selected since (i) it has the longest AERONET data record ( $N=1573$ days) during the period 2001-2005, and (ii) it has a very high OC+BC presence $(71.3 \%)$, second only to Alta Floresta $(77.78 \%)$. Analogous criteria were used to select sites dominated by dust, urban-industrial SU and sea salt aerosol. As a result, the following sites that are representative of the dominant aerosol types were selected:

- Dust: Banizoumbou, Niger $\left[2.665^{\circ} \mathrm{E}, 13.541^{\circ} \mathrm{N}\right.$, elevation $=t 250 \mathrm{~m}]$

- Biomass burning: Mongu, Zambia $\left[23.151^{\circ} \mathrm{E}\right.$, $15.254^{\circ} \mathrm{S}$, elevation $\left.=1107 \mathrm{~m}\right]$

- Urban-industrial pollution: Goddard Space Flight Center (GSFC)-Washington, US [76.840 ${ }^{\circ} \mathrm{W}, 38.992^{\circ} \mathrm{N}$, elevation $=87 \mathrm{~m}$ ]

- Marine: Lanai, Hawaii [156.922 ${ }^{\circ}$ W, $20.735^{\circ} \mathrm{N}$, elevation $=20 \mathrm{~m}]$

Regarding the selection of temporal data at these sites, daily-averaged AERONET Level 2.0 Version 2 qualityassured and cloud-screened data for each site were aligned (i.e. filtered for synchronous values) with the daily-averaged GOCART AOD data. The day corresponding to the peak $\% \mathrm{DU}$ at Banizoumbou, peak \%(BC+OC) at Mongu, peak $\% \mathrm{SU}$ at GSFC-Washington, and peak \%SU at Lanai was then identified. This allowed for selection of the AERONET daily-averaged Level 2.0 Version 2 AVSDs used in this study. The aerosol composition ranked by dominant aerosol type for each of the four sites is shown in Table 1 .

\section{Methodology}

In Sect. 3.1 we briefly describe some anomalies associated with the fitting of key aerosol types using the bi-lognormal fitting procedure used by AERONET. Section 3.2 presents a potential improvement of this approach by lifting constraints on the mode separation point and performs a sensitivity analysis. Finally, in Sect. 3.3 we provide a general multi-modal fitting approach based on Gaussian mixtures. The different approaches are illustrated by using the case of dominant marine (sea salt) aerosol at Lanai to provide a context.

\subsection{AERONET bi-lognormal fitting}

The AVSD is usually assumed to be bi-modal so as to distinguish between a "fine" (accumulation) mode containing small particles $(<\approx 0.6 \mu \mathrm{m})$ and a "coarse" mode containing larger aerosol particles (Omar et al., 2005). With reference to Eq. (1), this partition of the AVSD into $n=2 \log$ normal modes - a fine (f) mode and a coarse (c) mode therefore requires the calculation of six secondary parameters: $V_{\mathrm{f}}, V_{\mathrm{c}}, r_{\mathrm{f}}, r_{\mathrm{c}}, \sigma_{\mathrm{f}}$ and $\sigma_{\mathrm{c}}$. The estimation of these parameters by the AERONET retrieval algorithm proceeds as follows. Firstly, the total volume size distribution $\mathrm{d} V / \mathrm{d} \ln r$ is divided into two parts at a radial mode separation point $r_{\mathrm{s}}$. 
Table 1. Data set derived from GOCART global chemical data comprising the four dominant aerosol type cases studied in this work. Note that SS at Lanai is the least "dominant" aerosol type case, with marine aerosol being mixed with other aerosols in the proportion $\approx 60 \%$ : $40 \%$.

\begin{tabular}{llrrrrrr}
\hline AERONET site & Peak date & SU & OC & BC & DU & SS & OC+BC \\
\hline Banizoumbou & $16 / 03 / 2005$ & $1.02 \%$ & $0.74 \%$ & $0.31 \%$ & $97.91 \%$ & $0.03 \%$ & $1.04 \%$ \\
Mongu & $14 / 08 / 2003$ & $5.61 \%$ & $77.36 \%$ & $16.76 \%$ & $0.22 \%$ & $0.05 \%$ & $94.12 \%$ \\
GSFC-Washington & $17 / 08 / 2005$ & $87.53 \%$ & $8.31 \%$ & $2.72 \%$ & $1.38 \%$ & $0.05 \%$ & $11.04 \%$ \\
Lanai & $21 / 02 / 2002$ & $28.92 \%$ & $5.31 \%$ & $2.31 \%$ & $3.32 \%$ & $60.14 \%$ & $7.61 \%$ \\
\hline
\end{tabular}

Fine particles of radii $r<r_{\mathrm{s}}$ contribute to the fine-mode volume concentration $V_{\mathrm{f}}$, while coarse particles with radii $r>r_{\mathrm{s}}$ contribute to the coarse-mode volume concentration $V_{\mathrm{c}}$. Values of other secondary (derived) parameters - such as the volume geometric mean radii $r_{\mathrm{f}}$ and $r_{\mathrm{c}}$, volume geometric standard deviations $\sigma_{\mathrm{f}}$ and $\sigma_{\mathrm{c}}$, and the fine-mode fraction $\eta$ (the fraction of the total volume concentration due to the fine mode) - are then calculated from the AVSD by integrating to and from the separation point $r_{\mathrm{s}}$. The equations necessary for their calculation are presented in Appendix A. To calculate $r_{\mathrm{f}}$ one sets $r_{1}=0.05 \mu \mathrm{m}$ and $r_{2}=r_{\mathrm{s}}$ and then exponentiates the value of $\ln r_{V}$ obtained. Conversely, to calculate $r_{\mathrm{c}}$ one sets $r_{1}=r_{\mathrm{s}}$ and $r_{2}=15 \mu \mathrm{m}$ and then exponentiates the value of $\ln r_{V}$ obtained. Similarly, to calculate the geometric fine-mode standard deviation $\sigma_{\mathrm{f}}$ one sets $r_{1}=0.05 \mu \mathrm{m}$ and $r_{2}=r_{\mathrm{s}}$ in Eq. (A4), and to calculate $\sigma_{\mathrm{c}}$ one sets $r_{1}=r_{\mathrm{s}}$ and $r_{2}=15 \mu \mathrm{m}$. The AERONET Level 2.0 Version 2 inversion algorithm provides the values of all of these parameters, including the value of the separation point $r_{\mathrm{s}}$ upon which they all depend. At present, the code estimates $r_{\mathrm{s}}$ by finding the local minimum within the size interval $0.439 \leq r \leq 0.992 \mu \mathrm{m}$ (Dubovik et al., 2000). For comparison, the CALIPSO Automated Aerosol Classification and Lidar Ratio Selection Algorithm (Omar et al., 2009) refers to $r_{\mathrm{s}}$ as the "fine cut-off radius" and sets it to $1.0 \mu \mathrm{m}$ for all aerosol types classified ("dust", "smoke", "clean continental", "polluted continental" and "polluted dust"), apart from "clean marine" aerosol, which has $r_{\mathrm{s}}$ set at $0.6 \mu \mathrm{m}$. The CALIPSO separation point (with the exception of marine aerosol) is therefore fixed at the upper limit of the AERONET operational range.

In the context of AERONET Level 2.0 Version 2 retrievals, the integrals are discrete since $\mathrm{d} V / \mathrm{d} \ln r$ is provided in 22 logarithmic bins. In order to investigate the accuracy of performing numerical integration with lognormal radial bins, we calculated the integral by first of all fitting $\mathrm{d} V(r) / \mathrm{d} \ln r$ with a piecewise interpolation between the 22 equidistant logarithmically spaced points provided in the radial size range $r_{1}=0.05 \mu \mathrm{m}$ and $r_{2}=15 \mu \mathrm{m}$ in Eq. (A1). We then doubled the number of interpolation points and recalculated the integral. This was then repeated until the integral converged. The rationale for interpolating the AVSD is twofold:
1. In order to decrease the radial step size and hence improve the validity of the sensitivity analysis applied to the position of the mode separation point $r_{\mathrm{s}}$ described in Sect. 3.2

2. In order to avoid spikes in the errors propagated using the Gaussian mixture method (GMM) described in Sect. 3.3 that are caused by jaggedness resulting from straight line connections across 22 discrete bins.

For the case of peak marine (sea salt) AVSD at Lanai, Fig. 1 shows how successive doubling of the number of interpolation points leads to a suitable smoothing of the AVSD without introducing spurious features. The legend of Fig. 1 shows that convergence to 6 decimal places is achieved when the number of interpolation points $N$ is in the range $1408 \leq N \leq 2816$ points - i.e. when there is approximately a 100 -fold increase in the radial grid resolution (=2200 points). At this resolution, it was found that the standard error associated with the GMM method described in Sect. 3.3 was stable.

Regarding the accuracy of the AERONET retrieval (the grey band in Fig. 1), the overall uncertainty in AOD data (under cloud-free conditions) is \pm 0.01 for wavelengths longer than $440 \mathrm{~nm}$, and \pm 0.02 for shorter wavelengths (Dubovik et al., 2000), and the error in aerosol AVSD is estimated to be $<10 \%$ for particle radii between $0.1 \mu \mathrm{m}$ and $7 \mu \mathrm{m}$ (see Dubovik et al., 2000). While this is true near the maxima of the distribution, the errors can be as large as $35 \%$ for the lowest AVSD values in this particle range (Dubovik et al., 2002). Furthermore, at the edges of the AVSD $(r<0.1 \mu \mathrm{m}$ and $r>7 \mu \mathrm{m}$ ) the accuracy of the retrieval drops significantly because of the low sensitivity of aerosol scattering at $440,670,870$ and $1020 \mathrm{~nm}$ to particles of these sizes (Dubovik et al., 2002). Correspondingly, the retrieval errors rise sharply to 80-100\% at the edges but do not significantly affect the derivation of the secondary microphysical parameters because typically the value of the AVSD is very low there (Dubovik et al., 2002). To provide a conservative uncertainty context for the results presented here, AERONET AVSDs are overlaid with an error band that is $10 \%$ at peaks in the interval $1 \leq r \leq 7 \mu \mathrm{m}, 35 \%$ at local minima in this range, and $100 \%$ in edge regions when $r<0.1 \mu \mathrm{m}$ and $r>7 \mu \mathrm{m}$. Between these thresholds, the error is interpolated on an 


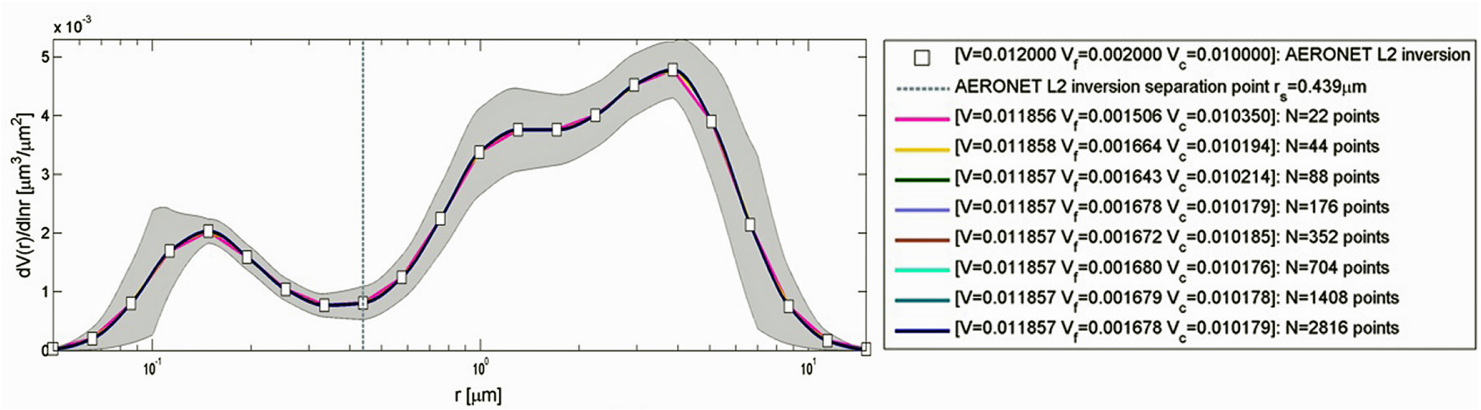

Fig. 1. Interpolation of the AVSD with between 22 and 2816 equidistant logarithmically spaced points ( 7 doublings) for dominant marine (sea salt) aerosol at Lanai on 21 January 2002. Only the interpolations with 22 points (pink) and 44 points (yellow) show visible deviations from the interpolation having the maximum 2816 points. Also shown is the value of the mode separation point $r_{\mathrm{s}}=0.439 \mu \mathrm{m}$ provided by the AERONET retrieval on this day. The grey band is the uncertainty on the AERONET AVSD obtained by following the approach described in the text.

equidistant, logarithmically spaced grid to ensure a smooth transition. Note that the overall trend with increasing number of points is as follows: $V, V_{\mathrm{f}}$ and $V_{\mathrm{c}}$ were all found to converge with increasing $N$ but did not converge asymptotically to the values given by the AERONET Level 2.0 Version 2 inversion retrieval. In particular when comparing with the quoted AERONET values, the interpolated value of $V$ is slightly lower (by $1.19 \%), V_{\mathrm{f}}$ is moderately lower $(16.20 \%)$ and $V_{\mathrm{c}}$ is slightly higher $(1.81 \%)$ - but all well within the prescribed AERONET uncertainty band.

In Fig. 3 (in Sect. 3.2), the AERONET-retrieved AVSD together with the associated bi-lognormal fit reconstructed from the AERONET-quoted values of the secondary microphysical parameters is shown. Note that three goodness-offit statistics are also provided: the mean of the residuals $b$, the standard error of the fit $s$, and the degrees-of-freedomadjusted $R^{2}$, which measure the difference between the interpolated AERONET AVSD and the bi-lognormal reconstructed using the secondary parameters in Eq. (1) for $n=2$ modes. All data-model comparisons in this work are accompanied by these measures of bias, location and spread $(b, s$ and $R^{2}$ respectively). Figure 3 clearly shows that in the case of maritime (sea salt) aerosol the fit to the fine mode is good but the fit to the coarse region is inappropriate - both from the perspective of fitting the "double hump" with a single broader peak, and from the perspective of the overall amplitude in this region. Given that the double hump occurs in the coarse region, it is possible that it is caused by the existence of a mixture of two coarse populations arising perhaps from (a) two different aerosol types, (b) fresh aerosol with an aged component, or (c) some combination of these. In any case, it appears that the mode separation point $r_{\mathrm{s}}$ for this AVSD leads to a bi-lognormal fit that is good for the fine mode but poor for the coarse mode. The requirement for the total integrated volume concentration to remain constant means that, while it is feasible that the double-hump coarse-mode region can be better fit by changing the mode separation point, the fit to the fine-mode peak will necessarily have to worsen. This is suggestive of a need for handling the problem in a different way. With this in mind, in the next section, we present a method for unambiguously and automatically calculating the optimal location of $r_{\mathrm{S}}$ by optimizing the statistical measures $s$ and $R^{2}$.

\subsection{Optimized equivalent-volume (OEV) bi-lognormal fitting}

Since the AERONET code uses $r_{\mathrm{s}}$ to separate fine and coarse modes and then obtains the spectral AOD extinction and absorption and asymmetry factors for these modes, the location of $r_{\mathrm{s}}$ is central. Furthermore, the fact that such spectral parameters are being used to validate satellite retrievals of fine and coarse modes means that the role played by $r_{\mathrm{s}}$ is becoming more prominent. It is therefore important to test the assumption that bi-lognormals provide the best fit to the AVSD and, if so, to assess the impact of uncertainty in the value of $r_{\mathrm{S}}$ on derived microphysical parameters. For this purpose, we stepped $r_{\mathrm{s}}$ through the set of 2200 (interpolated) equidistant logarithmically spaced radial bins (excluding the end points). Then, using the interpolated volume concentration as a constraint, in each step, a bi-lognormal was fit to the AVSD and the secondary (derived) microphysical parameters $\left(V_{\mathrm{f}}, V_{\mathrm{c}}, r_{\mathrm{f}}\right.$, $r_{\mathrm{c}}, \sigma_{f}$ and $\sigma_{\mathrm{c}}$ ) and goodness-of-fit measures $\left(s\right.$ and $R^{2}$ ) were calculated and tabulated. While the 2198 fits obtained (minus the end points) fill a continuum, we show in Fig. 2 the result of applying this procedure to the AERONET AVSD radial bins in the range $0.1-7 \mu \mathrm{m}$ (the " $10 \%$ error range").

While Fig. 2 shows no discernable bias $b=0.000$ (to 3 decimal places) and a small and stable standard error $s \approx 0.001 \mu \mathrm{m}, R^{2}$ is much more sensitive to changes in $r_{\mathrm{s}}$ and reveals a peak value of $R^{2}=0.893$ at $r_{\mathrm{s}}=0.286 \mu \mathrm{m}$. This suggests a method for automating the detection of the optical value of $r_{\mathrm{S}}$ related to $\max \left(R^{2}\right)$. Despite appearing constant in the legend of Fig. 2, a unique trough was found to exist in the curve of $s-$ suggesting an optimal 


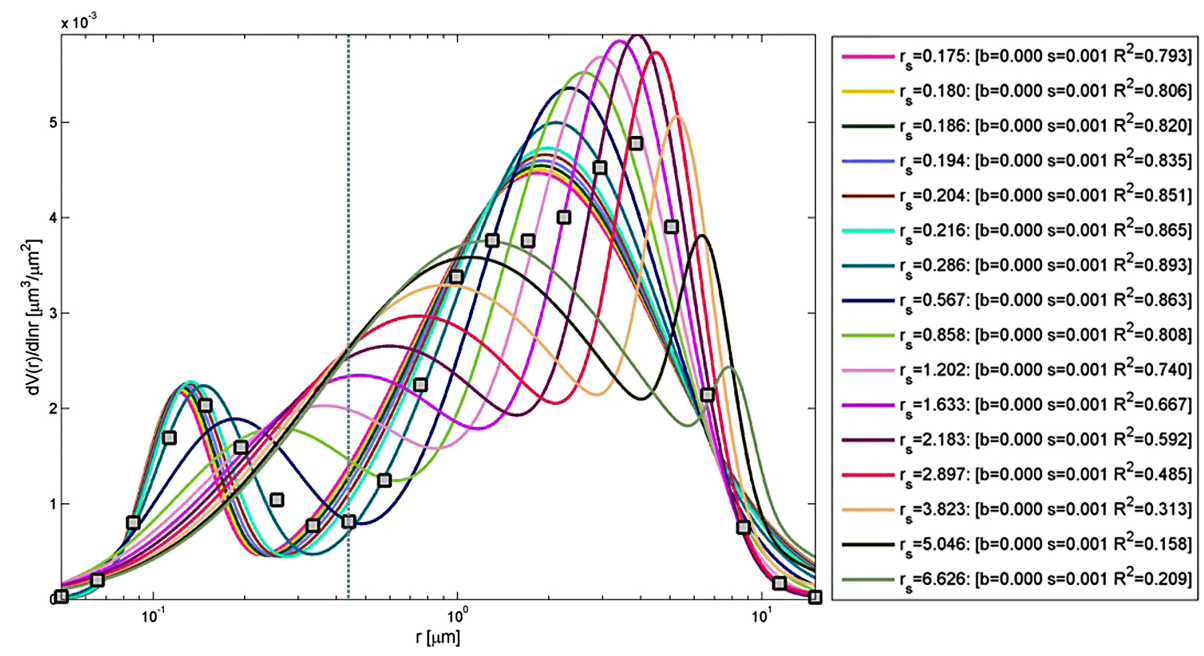

Fig. 2. Sensitivity analysis. The equivalent volume bi-lognormal fit to the AERONET AVSD data obtained by varying the mode separation point rs over a coarse 16-point radial grid spanning the interval 0.1 to $7 \mu \mathrm{m}$ for dominant marine (sea salt) aerosol at Lanai, Hawaii, on 21 January 2002. Note that the optimal mode separation point $\left(r_{\mathrm{S}}=0.303 \mu \mathrm{m}\right)$ described in Sect. 3.2 is obtained by applying the max $\left(R^{2}\right)$ and $\min (s)$ methods on the high-resolution interpolation grid of 2198 points. The grey squares are the values of the AERONET AVSD.

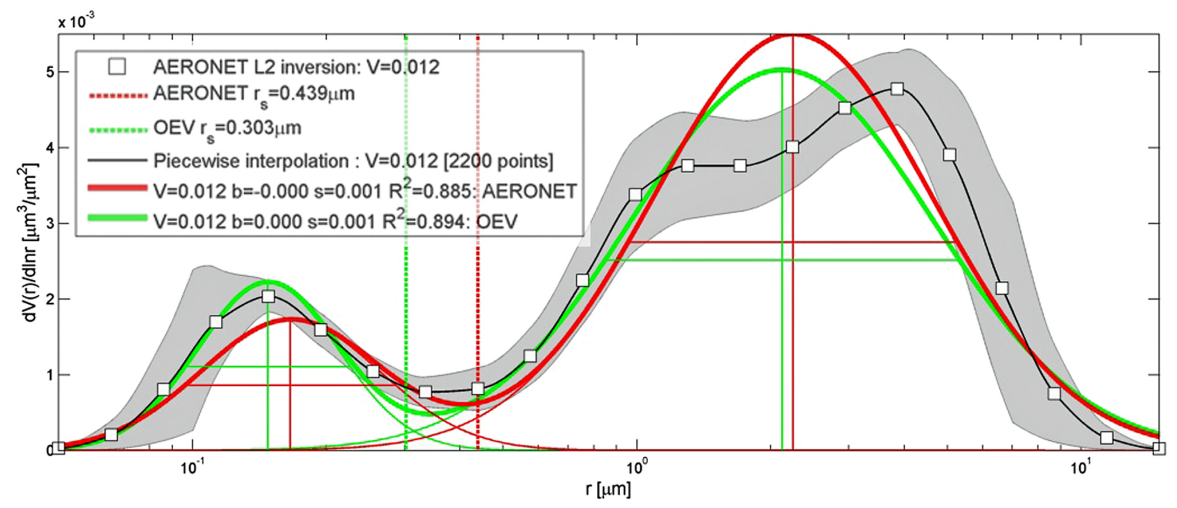

Fig. 3. Comparison of the interpolated AVSD for dominant marine (sea salt) aerosol at Lanai, Hawaii, on 21 January 2002 with the AERONET bi-lognormal fit and the optimized equivalent volume (OEV) fit. The grey band is the uncertainty on the AERONET AVSD.

separation related to $\min (s)$ when $r_{\mathrm{s}}=0.290 \mu \mathrm{m}(\approx 9 \%$ smaller than that obtained with $R^{2}$ ). These two estimates of $r_{\mathrm{s}}$ are significantly lower than the mode separation point $r_{\mathrm{s}}=0.439 \mu \mathrm{m}$ quoted by AERONET at this site on this day. Since we could not find a clear reason for favouring the $\max \left(R^{2}\right)$ method over the $\min (s)$ method, we decided to define the optimal $r_{\mathrm{s}}$ as the mean of the values obtained from the $\min (s)$ method and the $\max \left(R^{2}\right)$ method, i.e. $r_{\mathrm{s}}=$ $(0.290 \mu \mathrm{m}+0.315 \mu \mathrm{m}) / 2=0.303 \mu \mathrm{m}$. Figure 3 compares the results of the standard AERONET bi-lognormal fit with that obtained by optimizing the separation point using the method described above.

The OEV method developed above, based on optimiation of statistical measures of goodness of fit, obtains a new mode separation point that marginally improves the bi-lognormal fit to the $\operatorname{AVSD}\left(R^{2}=0.894\right.$ as compared with $\left.R^{2}=0.885\right)$.
However, while the improvement is only of the order of $1 \%$ in terms of $R^{2}$, there is a significant qualitative improvement. Visually, the fit to the fine mode with the new OEV method is much better, particularly on the smaller radius side of this marine aerosol AVSD. Its peak, while within the AERONET error in this region, appears to be slightly overestimated in amplitude but is well located. The fit to the coarse mode is also better in terms of the peak amplitude. It is also nearer to the raw data on the rising edge of the coarse-mode peak region at smaller radii. However, neither the AERONET bilognormal fit nor the new OEV fit are able to fit the double peak in the coarse-mode region. In Sect. 3.3, we present a second fitting method based on Gaussian mixture models to investigate whether or not the inclusion of additional modes can account for such features in the AVSD. 
With regard to the dependence of the secondary microphysical parameters on $r_{\mathrm{s}}$, we also performed a sensitivity analysis over the range $0.1 \leq r_{\mathrm{s}} \leq 7 \mu \mathrm{m}$ for the AVSD at Lanai, Hawaii, on 21 January 2002 interpolated with 2200 points as described in Sect. S1.1 of the Supplement. In the range of mode separation points $0.286 \mu \mathrm{m} \leq r_{\mathrm{s}} \leq 0.567 \mu \mathrm{m}$ (i.e. up to the edge of the coarse region $\approx 0.6 \mu \mathrm{m}$ ) the magnitude of the relative errors of the geometric mean radii $r_{\mathrm{f}}$ and $r_{\mathrm{c}}$, geometric standard deviations $\sigma_{\mathrm{f}}$ and $\sigma_{\mathrm{c}}$, and mode volumes $V_{\mathrm{f}}$ and $V_{\mathrm{c}}$ were found not to exceed $30 \%$ as can be seen in Table S1. However, steep gradients were observed outside this range. For example, in the range of mode separation points $0.439 \leq r_{\mathrm{s}} \leq 0.992 \mu \mathrm{m}$ used by the AERONET inversion code, the fine-mode parameters $r_{\mathrm{f}}, \sigma_{\mathrm{f}}$ and $V_{\mathrm{f}}$ reached large negative relative errors especially at the higher radius end where $r \approx 1 \mu \mathrm{m}$ (see Table S1). This suggests that the AERONET bi-lognormal fit is strongly under-predicting their values. The sensitivity analysis shows that apparently small differences in the value of the deduced separation point $r_{\mathrm{s}}$ can be seen to translate into large differences in the deduction of secondary microphysical parameters - and hence the shape of the reconstructed AVSD as can be seen visually in Fig. 3. The results of applying the sensitivity analysis to the three other dominant aerosol types are also included in Table S1 for reference and are discussed in Sect. 4. We also performed a sensitivity analysis of the effect of aerosol load as measured by the AOD at $1020 \mathrm{~nm}$ on the calculated secondary microphysical parameters. The results for a time window of 20 days around the marine aerosol peak (21 January 2002) at Lanai, Hawaii, are presented in Sect. S1.2. All microphysical parameters (except for $\sigma_{\mathrm{c}}$ ) show an increase with increasing $\mathrm{AOD}(1020 \mathrm{~nm})$. As expected, this proportionality is strongest in the case of the modal volume concentrations $V_{\mathrm{f}}$ and $V_{\mathrm{c}}$. The large spread of points at values of $\operatorname{AOD}(1020 \mathrm{~nm}) \leq 0.04$ in Fig. S2 is due to the fact that Level 2.0 Version 2 retrievals are less reliable at these low loads. Nonetheless, there is a substantial difference in the values obtained by the OEV fit and AERONET for loads $\operatorname{AOD}(1020 \mathrm{~nm})>0.04$, suggesting the need to reassess criteria on a case-by-case basis.

\subsection{Gaussian mixture model (GMM) multi-modal fitting}

While physical processes in the atmosphere often result in a bi-modal AVSD structure (Remer and Kaufman, 1998), it is known that the appearance of a third mode is also both realistic and likely (Dubovik and King, 2000). For example, a volcanic eruption may produce optically thick stratospheric aerosol, which adds a stable third compositional mode to the commonly appearing fine (accumulation) mode $(r<$ $0.6 \mu \mathrm{m})$ and coarse mode $(r>0.6 \mu \mathrm{m})$ composing tropospheric aerosol (Kaufman and Holben, 1996). The standard deviation of the AVSD is also known to vary substantially and to depend on the type of aerosol as well as prevailing atmospheric conditions (Dubovik and King, 2000). Furthermore, in the context of marine aerosol for example, it has been recently noted that the coarse mode is skewed and has a long tail at the lower-radius end (Sayer et al., 2012). The case of dominant marine sea salt at Lanai above presents an even more extreme situation where the coarse mode is doublehumped and the fit with a bi-lognormal is problematic. Recently, a double peak confined to the fine-mode region has also been observed (Eck et al., 2012). Despite such observations, the division of the AVSD into a single fine mode and a single coarse mode is still the norm. Here, we wish to assess whether or not there are statistically significant exceptions to the bi-lognormal case where additional modes should be included in the analysis. Of course, such discrepancies should be assessed carefully taking into account the uncertainty in AVSD measurements (particularly outside of the interval 0.1-7 $\mu \mathrm{m}$ ), and also the fact that the AERONET inversion code retrieves the AVSD from radiation measurements that have their own uncertainties. While the AERONET retrieval does not provide confidence intervals on the microphysical parameters (this is the reason bi-lognormal fits of Sects. 3.1 and 3.2 are presented without stated errors), the use of GMMs, however, allows for calculation of $95 \%$ confidence bands by propagating errors (see below). As a result, in what follows, errors will be placed also on the GMM model fit.

We wish to point out that, while the AVSD can also be fit directly with lognormals in the $r$ domain $(\mathrm{d} V(r) / \mathrm{d} r)$, we chose instead to fit the AVSD in the $\ln (r)$ domain (i.e. $\mathrm{d} V(r) / \mathrm{d} \ln r)$ with normal distributions. The reason is not just that there is mathematical equivalence between a lognormal distribution in $r$ and the analogous Gaussian distribution in $\ln (r)$, but that the lognormal distribution is skewed. Peaks in the AVSD in the $r$ domain are therefore always skewed. On the contrary, in the $\ln (r)$ domain, Gaussians are symmetrical and so an observed skew in a peak of the AVSD is due instead to a loss in goodness of fit arising from the inappropriateness of fitting it with a single (normal) mode, rather than due to any intrinsic asymmetry associated with the distribution itself. In the GMM method then, we fit the AVSD with a mixture of Gaussians under the proviso that the independent variable is $\ln (r)$. The GMM fit in this space has the generic form

$\frac{\mathrm{d} V(r)}{\mathrm{d} \ln r}=\sum_{i=1 . . n} a_{i} e^{-\left(\frac{\ln r-b_{i}}{c_{i}}\right)^{2}}$,

where, in this notation, $a_{i}$ is the "amplitude", $b_{i}$ is the "centroid" (or modal value), and $c_{i}$ is related to the width of each mode $i$ for a mixture containing up to $n$ discrete and independent modes. Comparing with the general n-lognormal equation of Eq. (1), the model coefficients $\left(a_{i}, b_{i}\right.$ and $\left.c_{i}\right)$ are related to the secondary (derived) microphysical parameters $\left(V_{i}, r_{i}\right.$ and $\left.\sigma_{i}\right)$ via the following set of relations: 

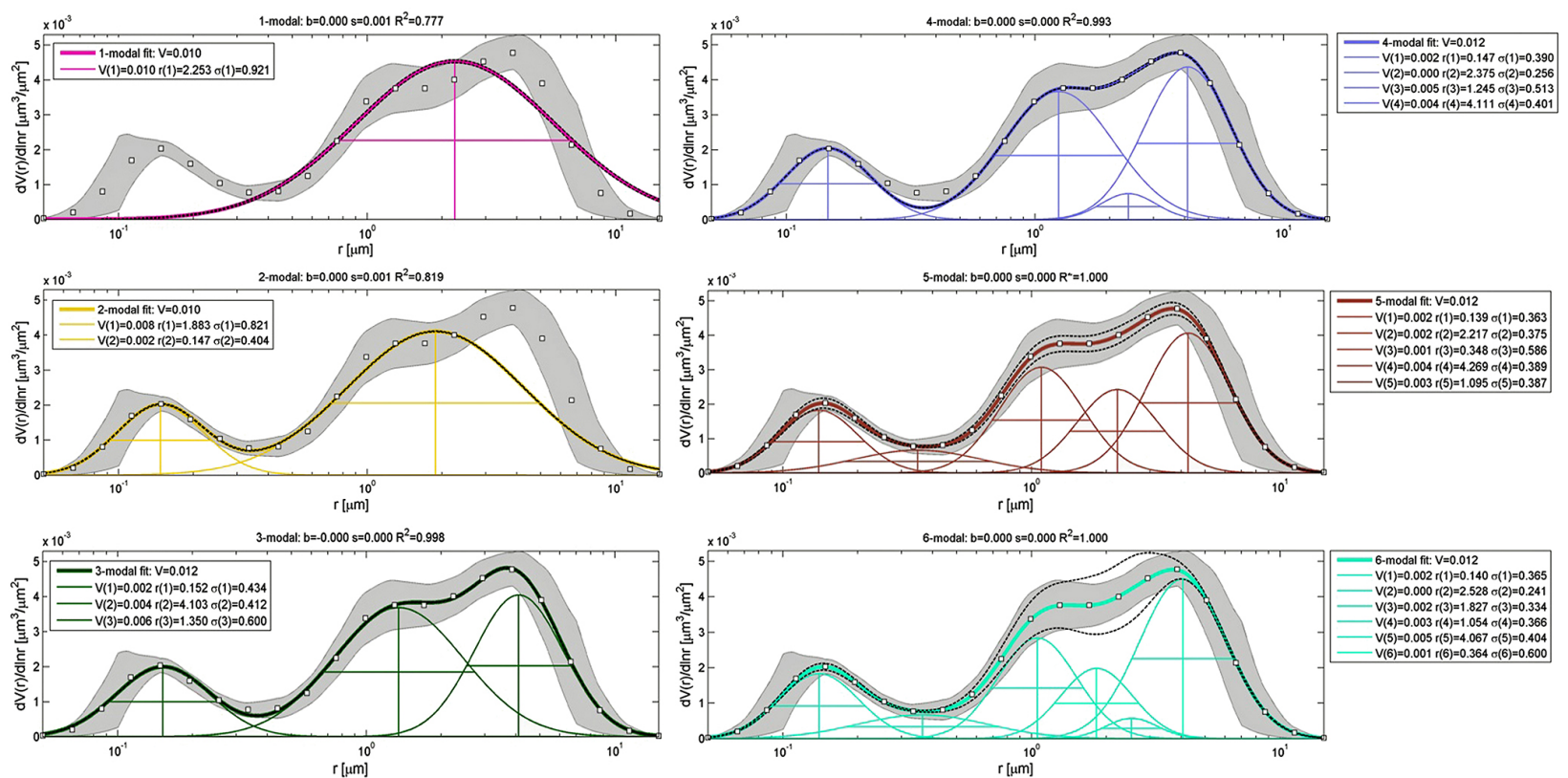

Fig. 4. Gaussian mixture model (GMM) one- to six-modal fits of the interpolated AVSD for dominant marine (sea salt) aerosol at Lanai, Hawaii, on 21 January 2002. The grey shaded region is the error on the AERONET data, and the black dotted lines (most visible in the fiveand six-modal plots) are the $95 \%$ confidence level curves on the fit.

$a_{i}=\frac{V_{i}}{\sigma_{i} \sqrt{2 \pi}} \leftrightarrow V_{i}=\sqrt{\pi}\left(a_{i} c_{i}\right)$,

$b_{i}=\ln r_{i} \leftrightarrow r_{i}=e^{b_{i}}$,

$c_{i}=\sigma_{i} \sqrt{2} \leftrightarrow \sigma_{i}=\frac{1}{\sqrt{2}} c_{i}$.

Our task then was to analyse an array of mixtures (containing 1-6 different modes); obtain the coefficients $a_{i}, b_{i}$ and $c_{i}$ for each mode; and then identify which mixture best fits the AVSD. We begin by noting that, while the GMM is a linear sum of modes, it is nonlinear in the coefficients - hence a nonlinear least squares fitting method was adopted. The fitting algorithm used to adjust the coefficients was a variant of the conjugate gradient method called the "trust region" method. More details on the application of this method are presented in Appendix C. To estimate the error of the fit, we followed the standard procedure of propagating errors (also described in Appendix C). As a result, the nonlinear least squares fitting algorithm provides values for $a_{i}, b_{i}$ and $c_{i}$ plus their upper and lower bounds at the $95 \%$ level of confidence $(p=0.05)$. Then, by making the assumption that the upper and lower confidence intervals are symmetrical about $a_{i}, b_{i}$ and $c_{i}$ (i.e. "two-tailed"), their standard errors $\operatorname{SE}\left(a_{i}\right), \operatorname{SE}\left(b_{i}\right)$ and $\operatorname{SE}\left(c_{i}\right)$ can be calculated - equal to the confidence interval divided by 1.96 (the value of the $z$ score at the $95 \%$ level). These standard errors then allow for an estimate of the upper and lower error bounds on the AVSD fit obtained for each mixture of $n$ modes. Figure 4 shows the results of applying the GMM method to the AVSD of peak marine aerosol at Lanai for the first $n=1 \rightarrow 6$ modes.

Clearly, three modes appear to be sufficient to fit the AVSD for this particular case. The addition of more modes does not contribute much improvement in the goodness of fit measures. For example, for the six-modal fit the value of $R^{2}=$ 1.000 is only marginally better than the value $R^{2}=0.998$ for the three-modal fit. Hence, an important question to answer at this point is, how can detection of the three-modal "optimum" be automated? For example, a detection algorithm based on seeking the maximum value of $R^{2}$ is likely to flag up the six-modal fit as the optimal fit to the above AVSD. In particular, care should be taken to ensure that additional modes are physical and not just artefacts of the fitting procedure. What is needed therefore is a stopping condition to find the optimal mixture. One way to do this is to define a statistic and then to perform a hypothesis test to assess whether or not adding an extra mode leads to a statistically significant improvement in the fit. Here, we adopt the protocol outlined by Harel (2009) and work with the square root of the degreesof-freedom-adjusted $R^{2}$ as a proxy for the Pearson productmoment correlation coefficient $\rho$. This is based on the assumption that the nesting procedure (i.e. adding more modes and therefore model parameters) does not cause much divergence to occur between the coefficient of determination $R_{\mathrm{d}}^{2}$ and the degrees-of-freedom-adjusted $R^{2}$ (defined in Eqs. B4 and B6 in Appendix B). This was verified for all of the dominant aerosol type cases studied here, and the results of the calculations are presented in Sect. S2 of the Supplement. The 
Table 2. Statistical testing of $R^{2}$ during application of the GMM fit to the interpolated AVSD of dominant marine (sea salt) aerosol at Lanai, Hawaii, on 21 January 2002. In the case of a single mode, statistical testing is not performed. In the case of both $n=2$ and $n=3$ modes, the lower confidence limit $\mathrm{CI}_{2}(1)$ of the larger-valued $F\left(\rho_{2}\right)$ is less than the upper confidence limit $\mathrm{CI}_{1}(u)$ of the lower-valued $F\left(\rho_{1}\right)$, and the $t$ Welch statistic being $>1.96$ shows that there is a statistically significant improvement in $\mathrm{R}^{2}$. In the case of $n=4$ modes, two things should be noted: firstly, that $F\left(\rho_{2}\right)<F\left(\rho_{1}\right)$ (i.e. a reduction in the improvement in the goodness of fit). Secondly, since the lower confidence limit $\mathrm{CI}_{1}(l)$ of the larger-valued $F\left(\rho_{1}\right)$ is greater than the upper confidence limit $\mathrm{CI}_{2}(u)$ of the lower-valued $F\left(\rho_{2}\right)$, this reduction is statistically significant; i.e. the addition of the fourth mode worsens the fit, and the optimal number of modes is therefore $n=3$.

\begin{tabular}{lrrrrrrrrr}
\hline$n$ Modes & $R^{2}(n)$ & $R^{2}(n+1)$ & $F\left(\rho_{1}\right)$ & $F\left(\rho_{2}\right)$ & $\mathrm{CI}_{1}(l)$ & $\mathrm{CI}_{1}(u)$ & $\mathrm{CI}_{2}(l)$ & $\mathrm{CI}_{2}(u)$ & $t$ Welch \\
\hline 1 & 0.777 & & & & & & & & \\
2 & 0.777 & 0.819 & 1.38 & 1.50 & 1.34 & 1.54 & 1.46 & 1.54 & 3.87 \\
3 & 0.819 & 0.998 & 1.50 & 3.80 & 1.46 & 3.84 & 3.76 & 3.84 & 76.26 \\
4 & 0.998 & 0.993 & 3.80 & 3.17 & 3.76 & 3.21 & 3.13 & 3.21 & 20.80 \\
\hline
\end{tabular}

percentage relative error (RE) between $R^{2}$ and $R_{\mathrm{d}}^{2}$ was found to be very small for GMMs containing 1-6 modes - reaching a maximum value of $\mathrm{RE}=0.060 \%$. Propagating this error into the square root of $R^{2}$ (the proxy for Pearson's $\rho$ ), we found that this had an effect only on the 4th decimal place and did not impinge on the results of the hypothesis-testing procedure (see below) at the $95 \%$ level. Having justified the use of the square root of $R^{2}$ as a proxy for Pearson's $\rho$, we then proceeded to construct confidence intervals on $\rho$ using the Fisher transform (Fisher, 1921):

$F(\rho)=\frac{1}{2} \ln \frac{1+\rho}{1-\rho}$,

where $F(\rho)$ is a transformed value of $\rho$ that follows approximately a normal distribution with standard error $\mathrm{SE}=$ $1 / \sqrt{ }(N-3)$ for a sample of $N$ points (Fisher, 1921). If we note that the 0.975 quantile of the normal distribution has a $z$ score of 1.96, then the upper and lower $95 \%$ confidence limits are simply $F(\rho) \pm 1.96 / \sqrt{N-3}$. We calculated these limits for the value of $\rho$ obtained for each GMM (1-6 modes). Two values of $F(\rho)$ (and hence $R^{2}$ ) show a significant statistical difference when the lower confidence limit of the larger $F(\rho)$ value does not overlap the upper confidence limit of the smaller $F(\rho)$ value. In the event of an overlap, the Welch $t$ statistic for unequal variances (Welch, 1947),

$t=\left|\frac{F\left(\rho_{1}\right)-F\left(\rho_{2}\right)}{\sqrt{\frac{1}{N_{1}-3}+\frac{1}{N_{2}-3}}}\right|$,

reports a significant statistical difference when $t>1.96$. In this way, a test was performed as modes were successively added to the Gaussian mixture. The optimal GMM fit occurs when adding a new mode does not lead to a significant statistical difference in $F(\rho)$ (or $t$ in the case of overlapping values) at the $95 \%$ level of confidence. The calculation is presented in Table 2 for the automatic identification of the optimal (three-mode) mixture pertinent to the case of maximum marine sea salt illustrating this section.
Figure 5 shows the resulting three-modal GMM fit $(b=$ $0.000, s=0.000, R^{2}=0.998$ ) to the AVSD. Comparing with the AERONET bi-lognormal fit ( $b=0.000, s=0.001, R^{2}=$ $0.885)$ and the OEV fit $\left(b=0.000, s=0.001, R^{2}=0.894\right)$ shown in Fig. 3, the result of fitting with the GMM is clearly both quantitatively and qualitatively better.

\section{Results}

The case of fitting the AVSD of dominant marine aerosol at Lanai with a bi-lognormal shows that things are not so simple but that fitting problems could be overcome with the GMM method. This motivates a study of other geo-locations where the aerosol composition is also clearly defined so as to assess under which conditions bi-lognormal fits are appropriate or not. With this in mind, in Table S3 in the Supplement accompanying this paper, we collect together the results of fitting the AVSD for each of the four dominant aerosol type cases with the methods introduced in Sects. 3.2 and 3.3.

Concerning the comparison of the goodness of fit obtained with the AERONET approach and the OEV method, in relation to the mode separation point, Table S3 shows that there are important differences. For peak dust, the value of $r_{\mathrm{s}}=0.439 \mu \mathrm{m}$ deduced by the AERONET inversion code is substantially smaller $(-94.1 \%)$ than that obtained by the OEV method $\left(r_{\mathrm{s}}=0.852 \mu \mathrm{m}\right)$. For biomass burning, urban $\mathrm{SU}$ and marine sea salt, the mode separation point $r_{\mathrm{s}}$ deduced by the AERONET inversion code is larger than that obtained by the OEV method: $r_{\mathrm{s}}=0.648 \mu \mathrm{m}$ versus $r_{\mathrm{s}}=0.546 \mu \mathrm{m}$, $r_{\mathrm{s}}=0.756 \mu \mathrm{m}$ versus $r_{\mathrm{s}}=0.528 \mu \mathrm{m}$, and $r_{\mathrm{s}}=0.439 \mu \mathrm{m}$ versus $r_{\mathrm{S}}=0.303 \mu \mathrm{m}$ respectively with relative errors of +18.7 , +30.2 and $+31.0 \%$. These differences translate into a direct impact on the goodness of fit as measured by $R^{2}$. In the case of dust, $R^{2}=0.913$ for the AERONET bi-lognormal fit and $R^{2}=0.978$ using the OEV method - where the deduced value of $r_{\mathrm{s}}$ is almost double that of AERONET. Nevertheless, the AVSD is clearly well fit with two modes (i.e. a bilognormal) but application of the OEV method is necessary to ensure a good fit in the "shoulder" region. For biomass 


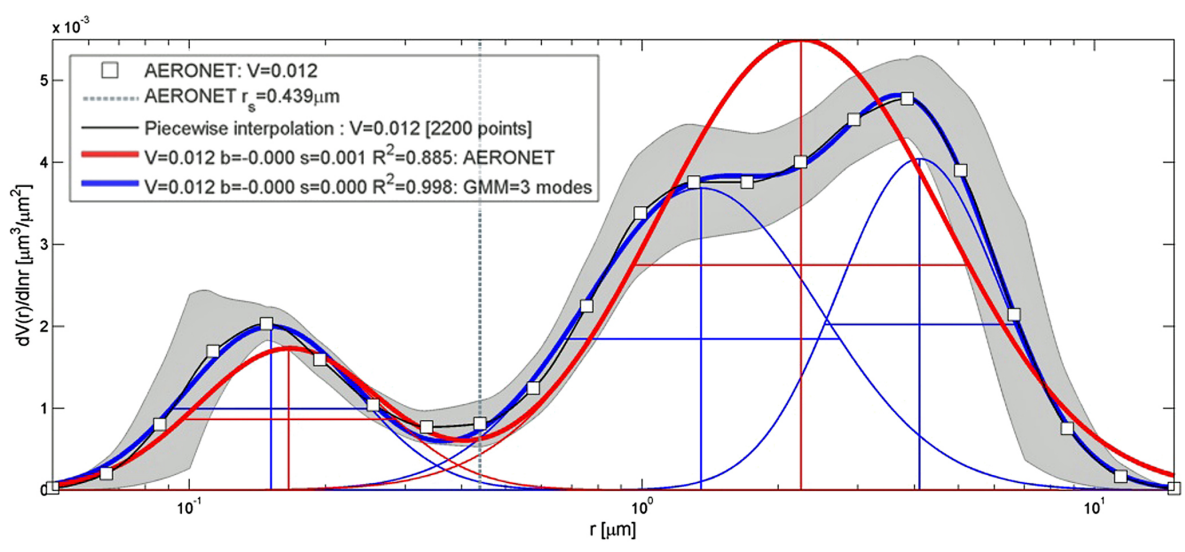

Fig. 5. Comparison of the interpolated AVSD for dominant marine (sea salt) aerosol at Lanai, Hawaii, on 21 January 2002 with the AERONET bi-lognormal fit and the optimal tri-modal Gaussian mixture model (GMM) fit. The grey band is the uncertainty on the AERONET AVSD.

burning and urban SU, the value of $R^{2}$ obtained with both AERONET and the OEV method are higher $\left(R^{2}>0.982\right)-$ suggesting that their AVSDs are very satisfactorily fit with a bi-lognormal distribution in both cases. Table S2 in the Supplement shows that $R^{2}=0.983$ for AERONET and $R^{2}=$ 0.985 for the OEV method in the case of biomass burning, and that $R^{2}=0.982$ for AERONET and $R^{2}=0.987$ for the OEV method in the case of urban SU. While Fig. $6 \mathrm{~b}$ and c suggest that there is almost no visual difference between the two fits for these two dominant aerosol cases, we will demonstrate later in this section that even the more noticeable difference in the mode separation point rs obtained for these two aerosol types (see Table S3 in the Supplement) do not translate into statistically significant changes in derived secondary microphysical parameters. As such, it appears that the AERONET fit is fine in these two cases. As we have seen, the situation is different for peak marine (sea salt) where, despite a small improvement in the fit provided by the OEV method, the value of $R^{2}$ does not exceed 0.894. As was seen in Sect. 3, the bi-lognormal fit is not appropriate for this case - which involves a substantial mixture of aerosol types (only $60 \%$ is sea salt).

With regard to the secondary microphysical parameters, the case of peak dust reveals another stark feature resulting from the existence of a shoulder in the distribution in the region: $0.4 \leq r \leq 1 \mu \mathrm{m}$. There is a large difference in the reported fine-mode radius of dust obtained by AERONET $\left(r_{\mathrm{f}}=\right.$ $0.195 \mu \mathrm{m})$ and the OEV method $\left(r_{\mathrm{f}}=0.361 \mu \mathrm{m}\right)$. While the optimal separation point $r_{\mathrm{s}}$ obtained with the OEV method produces a slightly better fit to the AERONET AVSD (as measured by $R^{2}$ ), its impact on the values of the secondary microphysical parameters is dramatic. With reference to Table $\mathrm{S} 1$, the tabulated entry closest to the optimal value obtained with the OEV method is $r_{\mathrm{s}}=0.858 \mu \mathrm{m}$. With this mode separation point, Table S1 shows that the size of the relative error (using AERONET values as a reference) is very high for the fine volume $(-115.9 \%)$ and the fine radius $(-87.0 \%)$ - i.e. the value quoted by AERONET $\left(r_{\mathrm{f}}=\right.$ $0.195 \mu \mathrm{m})$ is $87.0 \%$ lower than that found using the optimized fit bi-lognormal fit $\left(r_{\mathrm{f}}=0.365 \mu \mathrm{m}\right)$. In contrast, in the case of peak biomass burning at Mongu, the tabulated entry closest to the optimal OEV value is $r_{\mathrm{s}}=0.567 \mu \mathrm{m}$. With this mode separation point, the relative errors of the microphysical parameters are in good agreement with those derived by AERONET and are in the narrow range: $-3.3 \%$ (for $\sigma_{\mathrm{c}}$ ) to $+2.6 \%$ (for $\sigma_{\mathrm{f}}$ ). The same is true for peak urban SU at GFSC-Washington, where the tabulated entry closest to the OEV optimum is $r_{\mathrm{s}}=0.528 \mu \mathrm{m}$. The similarity of this value to that quoted by AERONET for this day $\left(r_{\mathrm{s}}=0.756 \mu \mathrm{m}\right)$ also translates into small relative errors, spanning the narrow range: $-9.0 \%$ (for $\sigma_{\mathrm{c}}$ ) to $+5.1 \%$ (for $r_{\mathrm{c}}$ ). The situation takes a turn for the worse in the case of peak marine aerosol. While both the AERONET and OEV methods point to similar mode separation points $\left(r_{\mathrm{s}}=0.885 \mu \mathrm{m}\right.$ and $r_{\mathrm{s}}=0.894 \mu \mathrm{m}$, respectively), referencing the closest tabulated entry of $r_{\mathrm{S}}=0.885 \mu \mathrm{m}$ in Table $\mathrm{S} 1$ shows that the finemode parameters $r_{\mathrm{f}}, \sigma_{\mathrm{f}}$ and $V_{\mathrm{f}}$ are strongly underestimated $(-53.69 \%$ to $-68.73 \%)$ and the coarse-mode parameters $r_{\mathrm{c}}, \sigma_{\mathrm{c}}$ and $V_{\mathrm{c}}$ are being overestimated with a magnitude of $\approx 15 \%$. Dust and marine aerosol microphysical parameters are highly sensitive to the location of the mode separation point $r_{\mathrm{s}}$. In order to assess whether or not the changes in the secondary microphysical parameters arising from application of the OEV method are statistically significant or not, we performed a two-tail paired $t$ test on the values arising from application of the OEV method with the value of each parameter as provided by AERONET. The test was performed at the $95 \%$ level of confidence whereby a value of $p<0.025$ reports a statistically significant difference. The results of performing this test for each of the four dominant aerosol types are presented in Table 3, which shows that there is a statistical difference between fitting the AVSD with AERONET's reconstructed bi-lognormal and the OEV bi-lognormal only in the case of dust and marine (sea salt) $V_{\mathrm{f}}, V_{\mathrm{c}}$ and $r_{\mathrm{f}}-$ 
a)

c)
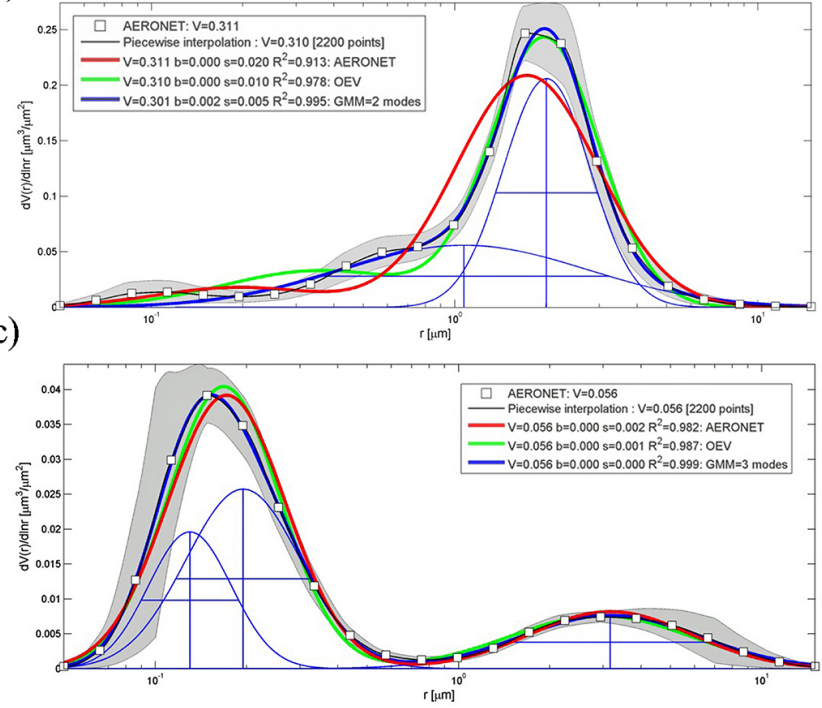

b)

d)
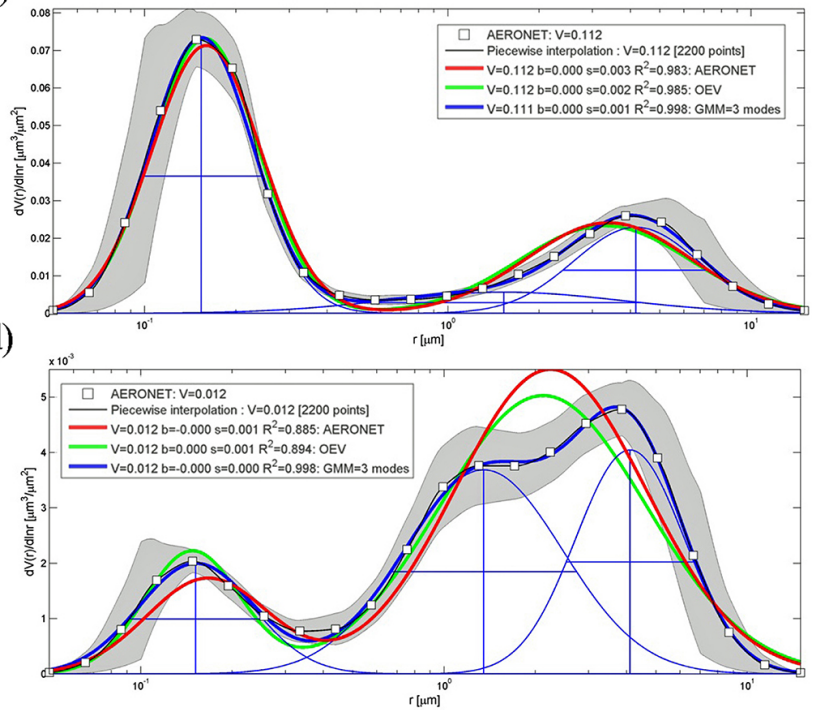

Fig. 6. Comparison of the interpolated AVSD, the AERONET bi-lognormal fit, the OEV bi-lognormal fit and the GMM optimal fit for (a) dominant dust aerosol at Banizoumbou, Niger, on 16 March 2005, (b) dominant biomass burning aerosol at Mongu, Zambia, on $14 \mathrm{Au}-$ gust 2003, (c) dominant urban SU aerosol at GSFC-Washington, US, on 17 August 2005, and (d) dominant marine (sea salt) aerosol at Lanai, Hawaii, on 21 February 2002. The grey band is the uncertainty on the AERONET AVSD.

Table 3. The results of applying a two-tailed paired $t$ test at the $95 \%$ level of confidence $(p<0.025)$ to ascertain whether or not the values of the secondary microphysical parameters obtained by the OEV method are statistically significant from those quoted by AERONET. Cases presenting a statistical difference are indicated by *.

\begin{tabular}{lllllll}
\hline Aerosol type & $p\left[r_{\mathrm{f}}\right]$ & $p\left[r_{\mathrm{c}}\right]$ & $p\left[\sigma_{\mathrm{f}}\right]$ & $p\left[\sigma_{\mathrm{c}}\right]$ & $p[V f]$ & $p\left[V_{\mathrm{c}}\right]$ \\
\hline Dust & $0.014^{*}$ & 0.039 & 0.456 & 0.083 & $0.013^{*}$ & $0.013^{*}$ \\
Biomass burning & 0.160 & 0.930 & 0.092 & 0.178 & 0.654 & 0.678 \\
Urban $\mathrm{SO}_{2}$ & 0.572 & 0.982 & 0.237 & 0.120 & 0.139 & 0.152 \\
Marine (sea salt) & $0.017^{*}$ & 0.035 & 0.048 & 0.132 & $0.012^{*}$ & $0.008^{*}$ \\
\hline
\end{tabular}

reinforcing our assertion that the AERONET fit of the AVSD of dust- and marine-dominated aerosol is problematic. Application of the OEV method both (1) improves the fit in these two dominant aerosol cases and (2) leads to significant differences in the values of the volume concentrations of the fine and coarse mode and also the fine-mode geometric radius.

While our emphasis is on a new parameterization of the size distribution, it is of course pertinent to ask what impact the changes imparted on derived secondary microphysical parameters by the OEV method may have on "final" products such as the AOD. In order to estimate this effect on, for example, the AOD at $1020 \mathrm{~nm}$, we refer the reader to Fig. S2 in the Supplement. The lower two panels in Fig. S2 show the regression of $V_{\mathrm{c}}$ and $V_{\mathrm{f}}$ respectively on the AOD at $1020 \mathrm{~nm}$ for the case of dominant marine aerosol at Lanai. For the OEV method the regressions have the form $V_{\mathrm{f}}=0.12 \times \mathrm{AOD}(1020)$ and $V_{\mathrm{c}}=0.93 \times \mathrm{AOD}(1020)$.
Inverting these linear relations, we find that for the fine mode $\mathrm{AOD}(1020) \approx 8.33 V_{\mathrm{f}}$ and $\approx 1.08 V_{\mathrm{c}}$. To estimate the effect of application of the OEV method as compared to the results of fitting the AVSD with the AERONET reconstructed bi-lognormal, we refer to entries in Tables S1 and S3 for marine aerosol where the AERONET separation point for this type of aerosol in Table S3 is $0.439 \mu \mathrm{m}$. The entry in Table $\mathrm{S} 1$ closest to this separation point is $r_{\mathrm{s}}=0.587$ with a relative error (for AERONET-OEV) of $\approx-28 \%$ for $V_{\mathrm{f}}$ and $\approx+7 \%$ for $V_{\mathrm{c}}$. We therefore expect that the $\mathrm{AOD}(1020)$ for the fine mode should be about $28 \%$ higher when using the OEV method than that predicted by AERONET and that the $\operatorname{AOD}(1020 \mathrm{~nm})$ for the coarse mode should be about $7 \%$ lower when using the OEV method than that predicted by AERONET.

Turning to the results of the GMM method, the fits to the AVSD for each of the four dominant aerosol type cases show a significant improvement over both those obtained by AERONET and using the OEV method. In Fig. 6 below, the interpolated AERONET AVSD retrieval is overlaid with the reconstructed AERONET bi-lognormal fit, the OEV bilognormal fit and the GMM optimal fit obtained by hypothesis testing.

Figure 6a shows that the GMM method flags up only peak dust aerosol as an $n=2$ bi-lognormal. In contrast, it fits peak biomass burning, urban SU and marine (sea salt) AVSDs in Fig. $6 \mathrm{~b}-\mathrm{d}$ with $n=3$ modes. While the qualitative appropriateness of these detections may be uncertain (see below), the results are statistically significant in the context of both the quoted error on the AERONET data and the deduced error 


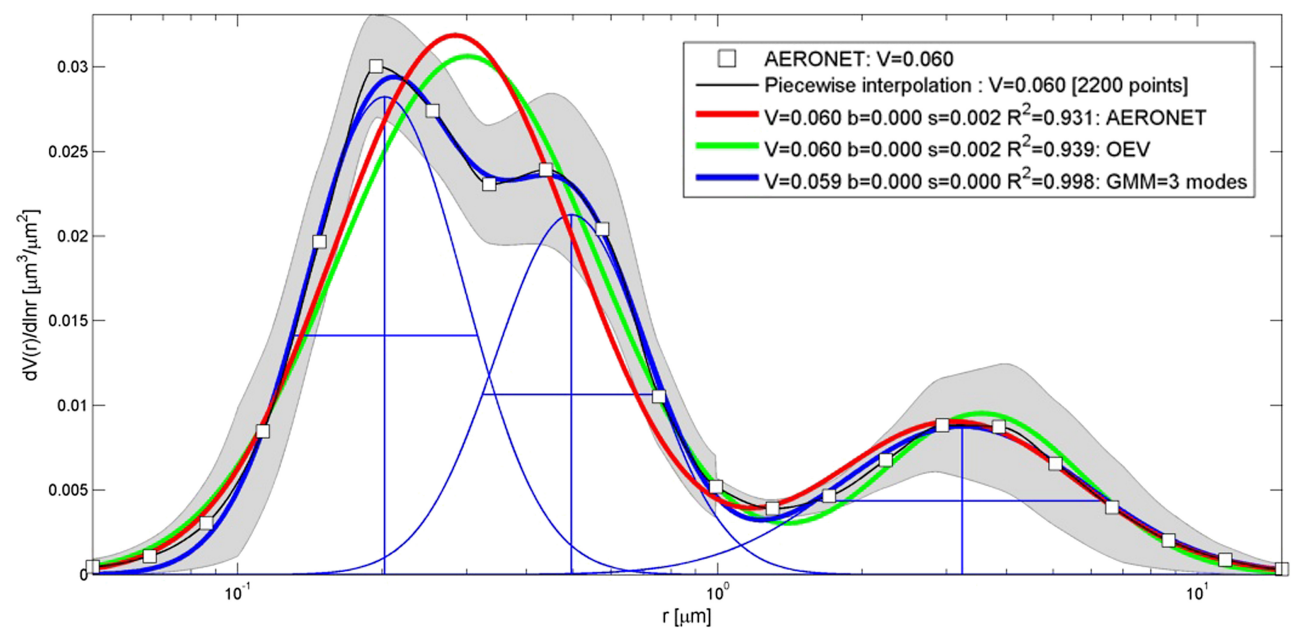

Fig. 7. Comparison of the interpolated AVSD, the AERONET bi-lognormal fit, the OEV bi-lognormal fit and the GMM optimal fit for the daily-averaged AERONET AVSD at Fresno on 11 February 2006 which displays a clear double hump in the fine-mode region. The grey band is the uncertainty on the AERONET AVSD.

on the GMM model. For example, in the case of peak dust aerosol (Fig. 6a), the GMM method does not fit the smallest fine mode which is marginally visible at $r \approx 0.1 \mu \mathrm{m}$. However, the GMM fit recovers the behaviour of the AVSD in the central shoulder region $\approx 0.4 \leq r \leq 1 \mu \mathrm{m}$ where there is no local minimum and does not need to refer to a mode separation point. Table S2 in the Supplement reveals that, in the case of dominant dust aerosol, the GMM method with two modes provides an improvement in the goodness of fit $\left(R^{2}=0.995\right)$ as compared to the OEV method where $R^{2}=0.979$. This improvement is also visually noticeable in Fig. 6a. In the case of peak biomass burning aerosol (Fig. 6b), all three fitting methods agree quite well for the fine mode despite the possible existence of a slight skew towards smaller radius particles. However, only the GMM method is able to properly fit the coarse mode - the AERONET bi-lognormal fit and the OEV method fit both slightly underestimate the location and amplitude of the coarse-mode peak. This is due to a skew in the coarse-mode peak. The GMM fit is able to correct for this effect by invoking the existence of a broad mode that peaks around $r \approx 0.2 \mu \mathrm{m}$. However, this peak is of low total volume concentration and spans too broad a range of particle radii - suggesting that it is physically perhaps less significant than the other two modes, and that arguably such an AVSD is approximately bi-lognormal. Note that the GMM method did not add a fourth mode to account for the possible skew in the fine-mode peak. This is likely to be due to the fact that the errors on the AERONET data are relatively large in the region of the skew. For peak urban SU aerosol (Fig. 6c), all three methods agree excellently on the shape of the coarse mode $(r>1 \mu \mathrm{m})$. In the fine-mode region, AERONET and the OEV method slightly over-predict the location of the fine-mode peak but in general are approximating its amplitude well. However, there is a clear skew in the fine region peak toward smaller radii. Here, despite large errors in the AERONET data at the low-radius end, the GMM method models the peak with a superposition of two modes - so as to fit this feature with two urban aerosol spikes. While this is physically plausible for urban pollution, we would argue that, just as for the case of biomass burning in Fig. 6b, the AVSD here is again approximately bi-lognormal. Finally, the case of peak marine (sea salt) aerosol (Fig. 6d) reveals a unique problem - that of fitting a double hump in the coarse-mode region. Only the GMM three-mode model is able to successfully reproduce the shape of the AVSD in this difficult-to-fit region. The fit with AERONET and the OEV method are unable to follow even small portions of the AVSD in the coarsemode region. For small particles below $r \approx 0.15-0.25 \mu \mathrm{m}$ the OEV fit is very good although it marginally overestimates the amplitude of the fine-mode peak. The AERONET approach is underperforming for this type of aerosol where mixtures are present (particularly at inhabited island sites and coastal regions). It is perhaps for this reason that only recently have models of pure marine aerosol been developed (Sayer et al., 2012). As mentioned in Sect. 3.3, a double-hump feature has also been observed in the fine-mode region associated with fog and cloud aerosol modification at Fresno (Eck et al., 2012). As a further illustration of the applicability of the methods developed in Sect. 3, in Fig. 7 we present the fits to the AVSD of this novel phenomenon. The goodness of fit of this atypical AVSD with the GMM method is $R^{2}=0.998$ as compared with values of $R^{2}=0.931$ and $R^{2}=0.939$ for the AERONET and OEV method bi-lognormal fits, respectively.

At this point, we present a brief assessment of the representativeness of the individual dominant aerosol type AVSDs for desert dust, biomass burning, urban SU and marine (sea salt) aerosol selected by referring to GOCART chemical output data. While we do not expect the daily-averaged AVSD 
Table 4. The ensemble of the 10 most desert-dust-dominated AVSDs at Banizoumbou (Niger), biomass-burning-dominated AVSDs at Mongu (Zambia), urban-SU-dominated AVSDs at GSFC-Washington (US) and marine (sea salt)-dominated AVSDs at Lanai (Hawaii) according to GOCART chemical daily-averaged data. The optimal number of modes resulting from application of the GMM method is given in the last column for each dominant aerosol type.

\begin{tabular}{|c|c|c|c|c|c|c|c|c|c|c|c|}
\hline $\begin{array}{l}\text { Desert } \\
\text { dust }\end{array}$ & $\% \mathrm{DU}$ & $\begin{array}{c}n \text { modes } \\
(\mathrm{GMM})\end{array}$ & $\begin{array}{l}\text { Biomass } \\
\text { burning }\end{array}$ & $\% \mathrm{OC}+\mathrm{BC}$ & $\begin{array}{c}n \text { modes } \\
(\mathrm{GMM})\end{array}$ & Urban & $\% \mathrm{SU}$ & $\begin{array}{c}n \text { modes } \\
(\mathrm{GMM})\end{array}$ & Marine & $\% \mathrm{SS}$ & $\begin{array}{c}n \text { modes } \\
(\mathrm{GMM})\end{array}$ \\
\hline $16 / 03 / 2005$ & 97.91 & 2 & $14 / 08 / 2003$ & 94.12 & 3 & $17 / 08 / 2005$ & 87.53 & 3 & $21 / 01 / 2002$ & 60.14 & 3 \\
\hline 09/12/2005 & 97.75 & 4 & $12 / 08 / 2001$ & 92.67 & 4 & $21 / 10 / 2002$ & 87.04 & 4 & $20 / 11 / 2003$ & 53.85 & 3 \\
\hline $07 / 12 / 2005$ & 97.74 & 3 & $20 / 08 / 2003$ & 92.64 & 3 & $05 / 10 / 2002$ & 86.79 & 3 & $17 / 01 / 2002$ & 53.78 & 3 \\
\hline $17 / 03 / 2005$ & 97.74 & 2 & $15 / 08 / 2003$ & 92.62 & 3 & $15 / 08 / 2005$ & 86.48 & 2 & $20 / 12 / 2001$ & 53.76 & 3 \\
\hline $04 / 11 / 2005$ & 97.69 & 4 & $11 / 08 / 2003$ & 92.48 & 3 & $20 / 07 / 2002$ & 85.85 & 3 & $19 / 12 / 2001$ & 49.66 & 3 \\
\hline $30 / 04 / 2005$ & 97.64 & 2 & $07 / 08 / 2004$ & 92.35 & 3 & $29 / 08 / 2001$ & 85.53 & 3 & $02 / 02 / 2002$ & 48.87 & 3 \\
\hline 05/04/2005 & 97.62 & 2 & $23 / 08 / 2004$ & 92.13 & 4 & $26 / 10 / 2005$ & 85.22 & 3 & $11 / 01 / 2002$ & 48.55 & 3 \\
\hline
\end{tabular}

cases selected to echo ambient climatological aerosol conditions at these sites since, for example, monthly averages are likely to be more representative, we extracted the 10 most dominant AVSDs for each case in order to place the most dominant cases in the context of a small ensemble of similar cases. Table 4 shows that the percentage contribution to the AOD from $\mathrm{SU}, \mathrm{BC}, \mathrm{OC}, \mathrm{DU}$ and $\mathrm{SS}$ is consistent for each ensemble. In particular, for the dustdominated ensemble the percentage contribution to the AOD from $\mathrm{DU}>97.62 \%$, for the biomass-burning-dominated ensemble the percentage contribution to the AOD from $\mathrm{OC}+\mathrm{BC}>92.13 \%$, for the urban-SU-dominated ensemble the percentage contribution to the AOD from $\mathrm{SU}>85.22 \%$, and for the marine-dominated ensemble the percentage contribution to the AOD from SS $>48.55 \%$ and includes a relatively strong SU component whose contribution is in the range $21.76 \% \leq \mathrm{SU} \leq 39.09 \%$. With regard to the optimal number of modes required to fit the AVSD, for the dustdominated ensemble, the GMM method suggests that AVSDs occurring during springtime (March and April) are best fit with two modes, but those occurring during late autumn and early winter (November and December) have a more complex composition requiring three and more commonly four modes. For the biomass-burning-dominated ensemble (all occurring in the month of August), the GMM method suggests that AVSDs are best fit with three or four modes. In the case of the urban-SU-dominated ensemble, no seasonal pattern is discernible and the GMM method suggests that AVSDs are best fit with three-four modes (an exception is 15 August 2005, which presents a relatively low contribution of DU and SS and whose AVSD is best fit with a bi-lognormal). Overall, it appears that the single dominant aerosol type cases analysed above are fairly typical of AVSD morphologies at these sites.

\section{Discussion}

Our study of peak aerosol type cases has revealed that AERONET bi-lognormal fits to the AVSD are not valid for the dominant dust and marine (sea salt) aerosol cases considered here. They are appropriate for the dominant biomass burning and urban SU aerosol cases but cannot explain the (small) effect of the skew of the coarse mode towards larger particles in the case of biomass burning or the skew of the fine-mode peak toward smaller particles in the case of urban SU. Relaxing the restriction on the location of the mode separation point used by AERONET with the OEV method slightly improved the traditional bi-lognormal fit in these latter cases - but had a more prominent impact in the cases of dominant dust and marine aerosol. In the case of dominant dust aerosol, while the AERONET bi-lognormal fit to the coarse mode is good on the high radius side, the fit on the low radius side of the coarse peak is poor and especially poor over nearly the entire fine-mode region. This was attributed to a strong underestimation of the mode separation point by AERONET. Correcting for this with the OEV method led to a significant improvement in the goodness of fit, with the fit to the coarse peak being almost indistinguishable for the raw AVSD. However, the constant total volume concentration constraint meant that this improvement was at the expense of the fit to fine-mode features, which worsened. In the case of marine (sea salt) aerosol, the goodness of fit using bi-lognormals was the lowest observed for all of the dominant aerosol type cases. Furthermore, the problem of fitting both the fine-mode peak and simultaneously a double peak in the coarse-mode region could not be attributed to miscalculation of the position of the mode separation point - suggesting strongly that two modes are not sufficient to fit this type of aerosol. Overall, the OEV method produced an improvement over the AERONET method in all four dominant aerosol type cases studied. It also provided a way to make explicit the sensitivity of secondary microphysical parameters 
to the location of the mode separation point $r_{\mathrm{s}}$. It was found that displacing $r_{\mathrm{s}}$ by even a single bin could lead to relative errors of the order of several 10s of percent on the derived parameters. While this is precisely what gives the OEV method its capacity for improving bi-lognormal fits, it highlights that some care should be taken when using the values of microphysical parameters provided by AERONET - particularly in the case of dust and marine aerosol.

In relation to the GMM method, in all cases, it was possible to fit dominant aerosol type cases with a very high goodness of fit which is almost indistinguishable from the raw AERONET AVSD. For peak dust, the best fit was found to be bi-modal, whereas for peak biomass burning (BC+OC), urban SU and marine (sea salt) the best fit was tri-modal. The use of iterated nonlinear least squares to obtain the microphysical coefficients was very efficient - although it was necessary to interpolate the AVSD with a 100-fold increase in the number of points (from 22 bins to 2200 bins) so as to avoid numerical instability (i.e. so that the propagated errors of the fit were stable at the $95 \%$ level of confidence). Using the square root of $R^{2}$ as a proxy for the Pearson productmoment correlation coefficient $\rho$ and applying the Fisher $z$ transform allowed us to perform a test for a statistically significant improvement in the fit with the addition of each additional mode. The null hypothesis at the $95 \%$ confidence level provided a stopping condition that enabled automatic identification of the optimal number of modes in the mixture. The GMM method, in addition to providing a better overall fit, provides important details concerning the amplitude, location and width of each mode contributing to the mixture and hence allows for determination of secondary microphysical parameters in the case of $n>2$ modes - something not currently possible with methods based on a single mode separation point. As such, the multi-modal content of the fit to the AERONET AVSD is obtained directly. We would like to point out that the retrieval algorithm used by AERONET obtains AVSDs that would have the same optical impact on radiances as the "real" one expected from chemical composition analyses. However, as we have seen, bilognormals, reconstructed from the microphysics (geometric radii, standard deviations and volume concentrations) quoted by AERONET, provide poor fits to the parent AVSDs from which they are calculated in the case of peak dust and marine sea salt size distributions. As such, the total volume concentration (analogous to the "weight" of the measurement in mass terms) is erroneously distributed between the two modes in these cases. What the OEV method does is to better simulate the location, spread and amplitude of the fine and coarse modes so that the optical analogue is also better. The GMM method then generalizes this approach to a greater number of modes.

\section{Conclusions}

In this work, the results of the GOCART model were used to rank and filter AERONET sites by aerosol type and used to select sites and individual daily-averaged records of the AERONET-retrieved AVSD. As a result, a data set was produced that comprised four daily-averaged AVSDs representative of four dominant aerosol types: dust, biomass burning (BC+OC), urban SU and marine SS. The AVSDs display a broad range of morphologies and provided a good test bed for comparisons of AERONET microphysical parameter fits with bi-lognormals against the two new fitting methods that form the crux of this paper. Firstly, a method (the OEV method) was developed based on applying sensitivity analysis to the mode separation point $r_{\mathrm{s}}$ and led to improvements in the bi-lognormal fitting procedure used by AERONET particularly in the case of dust. Furthermore, it is able to have potentially wider applicability since it is independent of the shape of the AVSD (and therefore the aerosol type). Secondly, the GMM method was developed for fitting the AVSD more generally with multiple $(n>2)$ modes, which produces consistently high goodness of fit for all of the dominant aerosol types studied, could be automated to detect an optimal number of physically plausible modes, and lifts restraints on both the total volume concentration and the need for additional mode separation points that would be required for example in a tri-lognormal equivalent of the OEV method. Furthermore, the GMM method gives access to the microphysical parameters associated with "higher" modes $(n>2)$ - not currently accessible by bi-lognormal fitting methods. In particular, this study showed that

1. the constraint of constant total integrated volume concentration allows bi-lognormal AVSDs (and hence all secondary microphysical parameters) to be calculated from knowledge of a single free parameter - the mode separation point $r_{\mathrm{s}}$,

2. deduction of $r_{\mathrm{s}}$ by detection of a local minimum in the size interval $0.439 \mu \mathrm{m} \leq r \leq 0.992 \mu \mathrm{m}$ is not always feasible - particularly in the case of desert dust where constraining $r_{\mathrm{s}}$ to this interval prevents the AERONET algorithm from obtaining the optimal bi-lognormal fit,

3. the OEV method is able to detect the optimum separation point instead by maximizing the goodness of fit (as expressed through $R^{2}$ ) independent of the shape of the AVSD and independent of the possible existence of a local minimum in the size interval $0.439 \mu \mathrm{m} \leq r \leq$ $0.992 \mu \mathrm{m}$,

4. it is possible to perform sensitivity analysis of the dependence of secondary microphysical parameters on (a) $r_{\mathrm{s}}$ and (b) the aerosol load (as measured by the AOD as a proxy), 
5. bi-lognormal distributions do not necessarily provide the best fit to AERONET AVSDs - especially in the case of desert dust and marine sea salt AVSDs or AVSDs that present double peaks either the fine- or coarse-mode regions,

6. the GMM method allows automatic detection of a statistically significant number of aerosol modes required to fit the AVSD on any given day and for a very diverse range of aerosol types.

With regard to estimation of the accuracy of the methods developed here, the mean bias $b$, standard error of the fit $s$, and the degrees-of-freedom-adjusted coefficient of determination $R^{2}$ were found to be very useful statistics for assessing the goodness of fit of the OEV method and the GMM method with respect to AERONET AVSDs. Consideration of the rate of change of $s$ and $R^{2}$ with respect to changes in $r_{\mathrm{s}}$ was what gave the OEV method its capacity to automate the detection of the optimal separation point. In the case of the GMM method, the calculation of $R^{2}$ for consecutive mixtures ( $n$ modes versus $n+1$ modes) in conjunction with Fisher statistics allowed for the development of a stopping condition to automatically detect the optimal aerosol mixture that best fits the AVSD. Note that, while the estimated errors on AERONET-retrieved AVSD are modelled, they serve only as a visual point of reference since they are still yet to be verified. Having said this, application of nonlinear least squares fitting and standard error propagation allowed $95 \%$ confidence bounds to be placed on the multi-modal fits to the interpolated AERONET AVSD in the GMM method.

The methods described here can be readily implemented in existing operational retrieval algorithms by coding a postprocessing module which reads in the AERONET-retrieved AVSD, interpolates the reported values of $\mathrm{d} V / \mathrm{d} \ln r$ over a finer radial grid and then (1) calculates secondary parameters using the equations presented in Appendix A by looping over a range of mode separation points (the OEV method), or (preferably) by performing nonlinear least squares fitting using multiple Gaussians in $\ln (r)$ space and performing nested hypothesis testing with reference to the equations presented in Appendices B and C (the GMM method).

Having applied the OEV and GMM methods to dominant aerosol types cases, we are currently applying the methods to study the temporal evolution of AVSDs during atmospheric phenomenon where ambient conditions are affected by the incursion of additional aerosol species that lead to abrupt changes in the chemical composition such as during volcanic eruptions, dense urban brown cloud episodes, desert dust storms and forest wildfire outbreaks, as well as modification of ambient aerosol conditions caused by the presence of fog and low-lying clouds.

It is hoped that the methods presented here will help contribute to the vast body of knowledge already provided by AERONET. AERONET retrievals are now being used for the accurate calculation of atmospheric broadband fluxes and aerosol radiative forcing, and have been shown to agree very reasonably with available coincident ground-based flux observations in desert regions (Derimian et al., 2008) and also globally (Garcia et al., 2008). Furthermore, new retrieval algorithms are being developed to extend the capability of AERONET and to transfer knowledge to new remote sensing domains. For example, Dubovik et al. (2011) developed an inversion procedure for spectral multi-angle, polarimetric, satellite observations from POLDER/PARASOL, and it is hoped that the new methods introduced here will help contribute additional information content as this exciting field evolves.

\section{Supplementary material related to this article is available online at http://www.atmos-meas-tech.net/7/ 839/2014/amt-7-839-2014-supplement.pdf.}

Acknowledgements. The authors would like to thank all the principal investigators of AERONET for their free provision of timely and high-quality aerosol retrieval data, Mian Chin and Tom Kucsera for making GOCART model data available during the years 2001-2005 for all AERONET sites at the AERONET data synergy portal, the MODIS rapid response team for making available true-colour images with fire sources from AQUA and TERRA, and David Giles and Brent Holben at NASA for curating the AERONET Data Synergy Tool at http://aeronet.gsfc.nasa.gov/cgi-bin/bamgomas_interactive. M. Taylor was supported by a Marie-Curie IEF-funded project "AEROMAP: Global mapping of aerosol properties using neural network inversions of ground and satellite based data", $\mathrm{CN}$ : 300515, and would like to thank the members of IERSD-NOA for excellent training in the field and, in particular, Spyros Lykoudis for useful discussions on statistical hypothesis testing of nested models.

Edited by: A. Kokhanovsky

\section{References}

Chin, M., Rood, R. B., Lin, S. J., Müller, J. F., and Thompson, A. M.: Atmospheric sulfur cycle simulated in the global model GOCART: Model description and global properties, J. Geophys. Res. Atmos., (1984-2012), 105, 24671-24687, 2000.

Chin, M., Ginoux, P., Kinne, S., Torres, O., Holben, B. N., Duncan, B. N., and Nakajima, T.: Tropospheric aerosol optical thickness from the GOCART model and comparisons with satellite and Sun photometer measurements, J. Atmos. Sci., 59, 461-483, 2002.

Derimian, Y., Leon, J.-F., Dubovik, O., Chiapello, I., Tanré, D., Sinyuk, A., Auriol, F., Podvin, T., Brogniez, G., and Holben, B. N.: Radiative properties of aerosol mixture observed during the dry season 2006 over M'Bour, Senegal (African Monsoon Multidisciplinary Analysis campaign), J. Geophys. Res. Atmos. (1984-2012), 113, D00C09, doi:10.1029/2008JD009904, 2008. 
Dubovik, O. and King, M. D.: A flexible inversion algorithm for retrieval of aerosol optical properties from Sun and sky radiance measurements, J Geophys. Res., 105, 20673-20696, 2000.

Dubovik, O., Smirnov, A., Holben, B. N., King, M. D., Kaufman, Y. J., Eck, T. F., and Slutsker, I.: Accuracy assessment of aerosol optical properties retrieval from AERONET sun and sky radiance measurements, J. Geophys. Res., 105, 9791-9806, 2000.

Dubovik, O., Holben, B., Eck, T. F., Smirnov, A., Kaufman, Y. J., King, M. D., Tanré, D., and Slutsker, I.: Variability of absorption and optical properties of key aerosol types observed in worldwide locations, J. Atmos. Sci., 59, 590-608, 2002.

Dubovik, O., Sinyuk, A., Lapyonok, T., Sinyuk, A., Mishchenko, M. I., Yang, P., Eck, T. F., Volten, H., Munoz, O., Veihelmann, B., van der Zander, W. J., Sorokin, M., and Slutsker, I.: Application of light scattering by spheroids for accounting for particle nonsphericity in remote sensing of desert dust, J. Geophys. Res., 111, D11208, doi:10.1029/2005JD006619, 2006.

Dubovik, O., Herman, M., Holdak, A., Lapyonok, T., Tanré, D., Deuzé, J. L., Ducos, F., Sinyuk, A., and Lopatin, A.: Statistically optimized inversion algorithm for enhanced retrieval of aerosol properties from spectral multi-angle polarimetric satellite observations, Atmos. Meas. Tech., 4, 975-1018, doi:10.5194/amt-4975-2011, 2011.

Eck, T. F., Holben, B. N., Reid, J. S., Giles, D. M., Rivas, M. A., Singh, R. P., and Goloub, P.: Fog- and cloud-induced aerosol modification observed by the Aerosol Robotic Network (AERONET), J. Geophys. Res., 117, D07206, doi:10.1029/2011JD016839, 2012.

Fisher, R. A.: On the "probable error" of a coefficient of correlation deduced from a small sample, Metron, 1, 3-32, 1921.

Garcia, O. E., Diaz, A. M., Exposito, F. J., Diaz, J. P., Dubovik, O., Dubuisson, P., Roger, J.-C., Eck, T. F., Sinyuk, A., Derimian, Y., Dutton, E. G., Schafer, J. S., Holben, B. N., and Garcia, C. A.: Validation of AERONET estimates of atmospheric solar fluxes and aerosol radiative forcing by ground-based broadband measurements, J. Geophys. Res. Atmos. (1984-2012), 113, D21207, doi:10.1029/2008JD010211, 2008.

Ginoux, P., Chin, M., Tegen, I., Prospero, J. M., Holben, B., Dubovik, O., and Lin, S. J.: Sources and distributions of dust aerosols simulated with the GOCART model, J. Geophys. Res., 106, 20255-20273, 2001.

Hansen, J. E. and Travis, L. D.: Light scattering in planetary atmospheres, Space Sci. Rev., 16, 527-610, 1974.

Harel, O.: The estimation of R 2 and adjusted R 2 in incomplete data sets using multiple imputation, J. Appl. Stat., 36, 1109-1118, 2009.

Hasekamp, O. P. and Landgraf, J.: Retrieval of aerosol properties over land surfaces: capabilities of multi-viewing-angle intensity and polarization measurements, Appl. Optics, 46, 3332-3344, 2007.

Kaufman, Y. J. and Holben, B. N.: Hemispherical backscattering by biomass burning and sulfate particles derived from sky measurements, J. Geophys. Res., 101, 19433-19445, 1996.

Kaufman, Y. J., Tanré, D., and Boucher, O.: A satellite view of aerosols in the climate system, Nature, 419, 215-223, 2002.

King, M. D., Byrne, D. M., Herman, B. M., and Reagan, J. A.: Aerosol size distributions obtained by inversion of spectral optical depth measurements, J. Atmos. Sci., 21, 2153-2167, 1978.
King, M. D., Kaufman, Y. J., Tanré, D., and Nakajima, T.: Remote Sensing of Tropospheric Aerosols from Space: Past, Present, and Future, B. Am. Meteorol. Soc., 80, 2229-2259, 2009.

Kokhanovsky, A. A., Deuzé, J. L., Diner, D. J., Dubovik, O., Ducos, F., Emde, C., Garay, M. J., Grainger, R. G., Heckel, A., Herman, M., Katsev, I. L., Keller, J., Levy, R., North, P. R. J., Prikhach, A. S., Rozanov, V. V., Sayer, A. M., Ota, Y., Tanré, D., Thomas, G. E., and Zege, E. P.: The inter-comparison of major satellite aerosol retrieval algorithms using simulated intensity and polarization characteristics of reflected light, Atmos. Meas. Tech., 3, 909-932, doi:10.5194/amt-3-909-2010, 2010.

Limpert, E., Stahel, W. A., and Abbt, M.: Log-normal distributions across the sciences: keys and clues, J. BioScience, 51, 341-352, 2001.

Omar, A. H., Won, J. G., Winker, D. M., Yoon, S. C., Dubovik, O., and McCormick, M. P.: Development of global aerosol models using cluster analysis of Aerosol Robotic Network (AERONET) measurements, J. Geophys. Res. Atmos, (1984-2012), 110, D10S14, doi:10.1029/2004JD004874, 2005.

Omar, A. H., Winker, D. M., Kittaka, C., Vaughan, M. A., Liu, Z., Hu, Y., Trepte, C. R., Rogers, R. R., Ferrare, R. A., Lee, K. P., Kuehn, R. E., Hostetler, C. A.: The CALIPSO automated aerosol classification and Lidar ratio selection algorithm, J. Atmos. Oceanic Technol., 26, 1994-2014, 2009.

O’Neill, N. T., Ignatov, A., Holben, B. N., and Eck, T. F.: The lognormal distribution as a reference for reporting aerosol optical depth statistics; Empirical tests using multi-year, multi-site AERONET sunphotometer data, Geophys. Res. Lett., 27, 33333336, 2000.

O’Neill, N. T., Eck, T. F., Smirnov, A., Holben, B. N., and Thulasiraman, S.: Spectral discrimination of coarse and fine mode optical depth, J. Geophys. Res., 108, 4559-4573, 2003.

Remer, L. A. and Kaufman, Y. J.: Dynamic aerosol model: Urban industrial aerosol, J. Geophys. Res., 203, 13859-13871, 1998.

Remer, L. A., Gasso, S. Hegg, D. A., Kaufman, Y. J., and Holben, B. N.: Urban/industrial aerosol: Ground-based Sun/sky radiometer and in situ measurements, J. Geophys. Res., 102, 16849-16859, 1997.

Remer, L. A., Kaufman, Y. J., Holben, B. N., Thompson, A. M., and McNamara, D. P.: Biomass burning aerosol size distribution and modeled optical properties, J. Geophys. Res., 103, 31879-31891, 1998.

Remer, L. A., Kaufman, Y.J, Tanre, D., Mattoo, S., Chu, D. A., Martins, J., and Holben, B. N.: The MODIS Aerosol Algorithm, Products, and Validation, J. Atmos. Sci., 62, 947-973, 2005.

Sayer, A. M., Smirnov, A., Hsu, N. C., and Holben, B. N.: A pure marine aerosol model, for use in remote sensing applications, J. Geophys. Res., 117, 1-25, 2012.

Steel, R. G. D. and Torrie, J. H.: Principles and Procedures of Statistics with Special Reference to the Biological Sciences, McGraw Hill, New York, 187, 287 pp., 1960.

Textor, C., Schulz, M., Guibert, S., Kinne, S., Balkanski, Y., Bauer, S., Berntsen, T., Berglen, T., Boucher, O., Chin, M., Dentener, F., Diehl, T., Easter, R., Feichter, H., Fillmore, D., Ghan, S., Ginoux, P., Gong, S., Grini, A., Hendricks, J., Horowitz, L., Huang, P., Isaksen, I., Iversen, I., Kloster, S., Koch, D., Kirkevåg, A., Kristjansson, J. E., Krol, M., Lauer, A., Lamarque, J. F., Liu, X., Montanaro, V., Myhre, G., Penner, J., Pitari, G., Reddy, S., Seland, Ø., Stier, P., Takemura, T., and Tie, X.: Analysis and quantifica- 
tion of the diversities of aerosol life cycles within AeroCom, Atmos. Chem. Phys., 6, 1777-1813, doi:10.5194/acp-6-1777-2006, 2006.

Textor, C., Schulz, M., Guibert, S., Kinne, S., Balkanski, Y., Bauer, S., Berntsen, T., Berglen, T., Boucher, O., Chin, M., Dentener, F., Diehl, T., Feichter, J., Fillmore, D., Ginoux, P., Gong, S., Grini, A., Hendricks, J., Horowitz, L., Huang, P., Isaksen, I. S. A., Iversen, T., Kloster, S., Koch, D., Kirkevåg, A., Kristjansson, J. E., Krol, M., Lauer, A., Lamarque, J. F., Liu, X., Montanaro, V., Myhre, G., Penner, J. E., Pitari, G., Reddy, M. S., Seland, Ø., Stier, P., Takemura, T., and Tie, X.: The effect of harmonized emissions on aerosol properties in global models an AeroCom experiment, Atmos. Chem. Phys., 7, 4489-4501, doi:10.5194/acp-7-4489-2007, 2007.
Welch, B. L.: The generalization of "Student's" problem when several different population variances are involved, Biometrika, 34, 28-35, 1947.

Whitby, K. T.: The physical characteristics of sulfur aerosols, Atmos. Environ., 12, 135-159, 1978.

Zhang, K., Wan, H., Wang, B., Zhang, M., Feichter, J., and Liu, X.: Tropospheric aerosol size distributions simulated by three online global aerosol models using the M7 microphysics module, Atmos. Chem. Phys., 10, 6409-6434, doi:10.5194/acp-10-64092010, 2010. 


\section{Appendix A}

\section{Calculation of secondary microphysical parameters}

From retrieved AERONET AVSDs, the volume concentration $V$ occupied by particles spanning the range of sizes $r=\left[r_{1}, r_{2}\right]$ is easily calculated by integrating the $\mathrm{d} V / \mathrm{d} \ln r$ over the complete range of values of $\ln r$ :

$C_{V}=\int_{r_{1}}^{r_{2}} \frac{\mathrm{d} V(r)}{\mathrm{d} \ln r} \mathrm{~d} \ln r$

In principle, the aerosol number size distribution (ANSD) $\mathrm{d} N(r) / \mathrm{d} \ln r$ or $\mathrm{d} N(r) / \mathrm{d} r$ could equally well be used instead of the AVSD (e.g. see King et al., 1978). The conversion between the volume and number distribution parameters is also straightforward (see for example Appendix A of Sayer et al., 2012). In particular, the spread $\sigma$ remains the same for both AVSD and ANSD (King et al., 1978). However, it has been found that the AVSD is preferable to the ANSD as it is more accurate when inverting optical data that are highly sensitive to aerosol particle size (Dubovik et al., 2011). The AERONET inversion code approximates the AVSD using trapezium rule integration (Dubovik and King, 2000), and, while the option of allowing the use of lognormal-shaped bins was included in the calculations of Dubovik et al. (2006), it has only recently been found that accurate modelling of POLDER/PARASOL observations can only be achieved by optimizing the shape of each radial size bin in this way (Dubovik et al., 2011). For an overview of the properties of lognormal distributions in the physical sciences we refer the reader to Limpert et al. (2001). By using a mode separation point $r=r_{\mathrm{s}}$, the fine mode fraction $\eta-$ a key parameter in aerosol forcing estimates (Kaufman et al., 2002) can then be calculated as follows:

$\eta=\frac{V_{\mathrm{f}}}{V_{\mathrm{f}}+V_{\mathrm{c}}}=\frac{\int_{r_{1}}^{r_{\mathrm{s}}} \frac{\mathrm{d} V(r)}{\mathrm{d} \ln r} \mathrm{~d} \ln r}{\int_{r_{1}}^{r_{\mathrm{s}}} \frac{\mathrm{d} V(r)}{\mathrm{d} \ln r} \mathrm{~d} \ln r+\int_{r_{\mathrm{s}}}^{r_{2}} \frac{\mathrm{d} V(r)}{\mathrm{d} \ln r} \mathrm{~d} \ln r}$.

The fine mode fraction reflects the contribution of the fine mode to the total volume concentration. For desert (mineral) dust in the Sahara and the Arabian Peninsula it is low $(\eta \approx 25 \%$ ); for multi-year averages of biomass burning in Africa and South America, and regional pollution in the eastern US, southeast Asian and Europe, the fine mode contribution is high and spans the range $92-95 \%$, while for maritime aerosol over the Pacific it is more moderate: $\approx 67 \%$ (Kaufman et al., 2002). Other important secondary microphysical parameters are statistical measures of central location and dispersion used to characterize individual aerosol modes in the AVSD. The logarithmic volume geometric mean radius (mean logarithm of radius) is a measure of the typical size of aerosol particles and is given by

$\ln r_{V}=\frac{\int_{r_{1}}^{r_{2}} \ln r \frac{\mathrm{d} V(r)}{\mathrm{d} \ln r} \mathrm{~d} \ln r}{\int_{r_{1}}^{r_{2}} \frac{\mathrm{d} V(r)}{\mathrm{d} \ln r} \mathrm{~d} \ln r}$.
The geometric mean radius is obtained by exponentiating the result. In addition, the geometric standard deviation is a measure of the spread ("width") of the particle mode(s) and is given by

$\sigma_{V}=\sqrt{\frac{\int_{r_{1}}^{r_{2}}\left(\ln r-\ln r_{V}\right)^{2} \frac{\mathrm{d} V(r)}{\mathrm{d} \ln r} \mathrm{~d} \ln r}{\int_{r_{1}}^{r_{2}} \frac{\mathrm{d} V(r)}{\mathrm{d} \ln r} \mathrm{~d} \ln r} .}$

\section{Appendix B}

\section{Comparative statistics measures}

Comparative statistics approaches necessarily involve the calculation of the differences (or residuals) between the model data $\left(\hat{y}_{i}\right)$ and the target AERONET AVSD data $\left(y_{i}\right)$. An initial picture is presented by the bias $b$ (or mean of the residuals), which, for $N$ pairs of data points ,is given by

$b=\frac{1}{N} \sum_{i=1}^{N} y_{i}-\hat{y}_{i}$.

This statistic is used to assess whether or not models systematically under-predict or over-predict. As a measure of the average difference, we avoid statistics such as the mean relative error and the $\chi^{2}$ statistic since, while dependent on residuals, they are fractional quantities and contain $y_{i}$ in the denominator. This can inflate their values in the tails of the AVSD where the values of $y_{i}$ are extremely small compared to regions, for example, dominated by modal ("fine" and "coarse") peaks. Instead, statistics involving sums of squares of the residuals were selected that are strongly sensitive to outliers - and hence better able to discriminate between good and bad fits. In particular, we calculated the sum of squares of the residual errors (SSE):

$\mathrm{SSE}=\sum_{i=1}^{N}\left(y_{i}-\hat{y}_{i}\right)^{2}$.

From this, the standard error of the fit $s$ was calculated,

$s=\sqrt{\frac{\mathrm{SSE}}{N-p-1}}$,

where $N$ is the number of points and $p$ is the number of independent model parameters. This is our choice of location (average) measure and is the unbiased sample estimator version of the traditional root mean square of the errors (RMSE). This measure is sensitive to outliers (due to its dependence on SSE) and is also an interval scale quantity - i.e. it has the same measurement units as $y_{i}$. In order to asses the dispersion (or spread) in the residuals of the fits, we decided to use a regression statistic known as the coefficient of determination $\left(R_{\mathrm{d}}^{2}\right)$,

$R_{\mathrm{d}}^{2}=1-\frac{\mathrm{SSE}}{\mathrm{SST}}$ 
where SST is the total sum of squares of the difference between the target AVSD data and its mean value $\bar{y}_{i}$ :

$\mathrm{SST}=\sum_{i=1}^{N}\left(y_{i}-\bar{y}_{i}\right)^{2}$.

$R_{\mathrm{d}}^{2}$ measures how well a model reproduces data in terms of the amount of the total variance it explains (Steel and Torrie, 1960) and ranges from 0 to 1 such that $R_{\mathrm{d}}^{2}=0.95$ is taken to mean, for example, that the model fit explains $95 \%$ of the total variance in the data. Care must be taken when using this statistic since models involving more modes have more model parameters $p$ and their improved fit is reflected in a smaller value of SSE. This results in a correspondingly gradual increase in the value of $R_{\mathrm{d}}^{2}$ with the number of parameters. To compensate for this effect, we therefore use, in this paper, the degrees-of-freedom-adjusted $R^{2}$ statistic which penalizes the value of $R_{\mathrm{d}}^{2}$ as extra parameters are included in the model:

$R^{2}=1-\frac{\operatorname{SSE}}{\operatorname{SST}}\left(\frac{N-1}{N-p-1}\right)$.

This is known to be a good indicator of fit quality when comparing nested models - i.e. a series of models each of which adds additional coefficients to the previous model (Harel, 2009) as is the case of the GMM method outlined in Sect. 3.3.

\section{Appendix C}

\section{The GMM fitting procedure and propagation of errors}

The identification of the best mixture in the GMM method of Sect. 3.3 is an optimization problem involving the minimization of the residuals between the observed AVSD data and the GMM model:

$\boldsymbol{\varepsilon}=\boldsymbol{y}-[f(\mathbf{x}, \boldsymbol{\beta})]$,

where $\boldsymbol{\varepsilon}$ is an $N \times 1$ vector of "residuals", $\boldsymbol{y}$ is an $N \times 1$ vector of "target" values (the AVSD), $x$ is an $N \times p$ "design matrix" for the model (in our case an $n$ Gaussian), $\boldsymbol{\beta}$ is a $p \times 1$ vector of "parameters" (the coefficients - i.e. the mode volumes, radii and standard deviations), and $f$ is a function of $x$ and $\beta$ (i.e. the linear sum of independent Gaussians expressed by Eq. (1) in Sect. 1 of this paper). Such problems cannot be solved using simple matrix techniques due to the nonlinear dependence of $\varepsilon$ on $\beta$ in the Gaussians. However, an approximate solution can be obtained by iteratively applying the nonlinear least squares method as follows:

- Step 1: provide an initial estimate for each coefficient.

- Step 2: produce the fit curve for the current set of coefficients.
- Step 3: adjust the coefficients using a conjugategradient method.

- Step 4: iterate the process, returning to step 2 until the fit converges.

This method was scripted in MATLAB using its in-built object-oriented scripting language, and required initial constraints to be placed on the values of the coefficients. For reproducibility of results obtained here, we provide the interested reader with the parameters used in the fitting procedure. The lower bounds were set to 0.0005 since the amplitudes, locations and spreads must be non-zero and positive for each GMM. The upper bounds were set to $3, \ln (15)$ and 3 for the amplitudes, log-locations and spreads respectively. The fit at each step was then obtained by minimizing the least absolute (total) residual (LAR). This "trust region" method also calculates the Jacobian of $f(x, \beta)$ to determine whether or not the fit is improving (based on the direction and magnitude of the previous adjustment). The minimum and maximum change in the coefficients for this finite difference Jacobian was set to $10^{-8}$. Regarding convergence criteria, we set the maximum number of model evaluations in each iteration to the default value of 600 and the maximum number of overall iterations to its default value of 400 . The stopping condition on the minimum value of the LAR was set to $10^{-6}$, which is $1 / 100$ th of the minimum volume concentration in our data set. This entire recipe was then repeated 8 times - being applied to GMMs containing one to eight modes in succession.

Confidence bounds for the optimal GMM (obtained with the fitting procedure that uses the stopping condition outlined in Sect. 3.3) were calculated by the standard approach of propagating errors. This could be achieved because a closed form exists for the optimal GMM as given by Eq. (1) for $n$ modes. For each independent mode

$f_{i}=a_{i} e^{-\left(\frac{\ln r-b_{i}}{c_{i}}\right)^{2}}$

the standard error $S E_{i}$ is given by

$\mathrm{SE}_{i}=$

$\sqrt{\left(\frac{\partial f_{i}}{\partial a_{i}} \times \mathrm{SE}\left(a_{i}\right)\right)^{2}+\left(\frac{\partial f_{i}}{\partial b_{i}} \times \mathrm{SE}\left(b_{i}\right)\right)^{2}+\left(\frac{\partial f_{i}}{\partial c_{i}} \times \mathrm{SE}\left(c_{i}\right)\right)^{2}}$

in terms of the partial derivatives

$\frac{\partial f_{i}}{\partial a_{i}}=a_{i} e^{-\left(\frac{\ln r-b_{i}}{c_{i}}\right)^{2}}$

$\frac{\partial f_{i}}{\partial b_{i}}=\frac{2 a_{i}\left(\ln r-b_{i}\right)}{c_{i}^{2}} e^{-\left(\frac{\ln r-b_{i}}{c_{i}}\right)^{2}}$

$\frac{\partial f_{i}}{\partial c_{i}}=\frac{2 a_{i}\left(\ln r-b_{i}\right)^{2}}{c_{i}^{3}} e^{-\left(\frac{\ln r-b_{i}}{c_{i}}\right)^{2}}$. 
The upper and lower $95 \%$ confidence bounds for the overall GMM fit are then obtained by noting that the standard errors of the modes also combine as root mean squares and are centred on the sum of the modes:

upper bound $=$

$$
\sum_{i=1 . . n} a_{i} e^{-\left(\frac{\ln r-b_{i}}{c_{i}}\right)^{2}}+1.96 \sqrt{\sum_{i=1 . . n}\left(\mathrm{SE}_{i}\right)^{2}}
$$

lower bound $=$

$$
\sum_{i=1 . . n} a_{i} e^{-\left(\frac{\ln r-b_{i}}{c_{i}}\right)^{2}}-1.96 \sqrt{\sum_{i=1 . . n}\left(\mathrm{SE}_{i}\right)^{2}}
$$

